\title{
Aposentadoria, Pressão Salarial e Desemprego por Nível de Qualificação*
}

\author{
José Márcio Camargo ${ }^{\dagger}$, Maurício Cortez Reis ${ }^{\ddagger}$
}

Sumário: 1. Introdução; 2. Mercado de Trabalho e Sistema de Aposentadorias no Brasil: Uma Breve Descrição das Principais Alterações nos Anos 80 e 90; 3. Dados; 4. Análise Descritiva; 5. Metodologia; 6. Evidências Empíricas para os Efeitos da Aposentadoria Domiciliar per Capita sobre o Desemprego; 7. Evidências Empíricas para as Taxas de Participação e de Não-emprego; 8. Conclusões; A. Efeitos da aposentadoria sobre o desemprego e a participação.

Palavras-chave: Desemprego; Aposentadoria; Nível de Qualificação.

Códigos JEL: J23; J26; J64.

Durante os anos noventa ocorreu um aumento significativo da taxa de desemprego no Brasil. Durante esse período também foi observado um aumento do valor da aposentadoria domiciliar per capita (a renda da aposentadoria dos domicílios dividida pelo número de moradores destes domicílios). Essas mudanças foram mais intensas para os trabalhadores com baixo nível de qualificação. De acordo com o argumento proposto neste artigo, a maior renda decorrente da aposentadoria aumentou o salário de reserva dos trabalhadores, ainda que os beneficios fossem recebidos por outros membros do domicílio que não os participantes da PEA. O salário de reserva mais elevado, por sua vez, teria gerado um aumento da pressão salarial, levando a maiores taxas de desemprego, assim como à maior incidência de desemprego de longo prazo. Os resultados, usando dados da PNAD de 1981 a 1999, mostram que maiores aposentadorias estão relacionadas a taxas mais altas de desemprego e de desemprego de longo prazo para os trabalhadores não-qualificados.

During the nineties the unemployment rate and the household retirement income per capita rose sharply in Brazil. It happened in a more intense way for the unskilled workers than for the other groups. According to the argument of this paper, the increase in household retirement income could have affected workers

\footnotetext{
* Os autores agradecem os comentários e sugestões de Gustavo Gonzaga, Eduardo Rios-Neto, Reynaldo Fernandes, Ricardo Paes de Barros, participantes do XXVI Encontro Brasileiro de Econometria e um parecerista anônimo.

${ }^{\dagger}$ Pontifícia Universidade Católica do Rio de Janeiro, Departamento de Economia. Rua Marquês de São Vicente, 225 - Gávea. CEP: 22453-900, Rio de Janeiro, RJ. Email: E-mail: jcamargo@econ.puc-rio.br.

‡IPEA. Rua Presidente Antônio Carlos, 51 - $14^{\circ}$ andar, sala 1409 - Centro. CEP: 20020-010, Rio de Janeiro, RJ. Email: E-mail: mcreis@ipea.gov.br.
} 
reservation wage, augmenting their wage pressure. In this way, wage pressure changes could have implied higher unemployment and long-term unemployment rates. The empirical evidence, using PNAD data from 1981 to 1999, shows that household retirement income has a positive effect on the unemployment rate and on the long-term unemployment rate for unskilled workers.

\section{INTRODUÇÃO}

Ao longo dos anos noventa, houve um importante aumento da taxa de desemprego aberto no Brasil. Dados da PNAD para indivíduos entre 25 e 59 anos nas áreas urbanas mostram que a taxa de desemprego aberto subiu de 3,1\% para 8,6\% da População Economicamente Ativa (PEA) entre 1990 e 1999. Os aumentos da taxa de desemprego foram mais acentuados entre os trabalhadores menos qualificados, com menores salários, do que entre os mais qualificados. Enquanto a taxa de desemprego dos trabalhadores qualificados aumentou 4,4 pontos percentuais entre 1990 e 1999, a taxa dos não-qualificados aumentou 6,64 pontos percentuais. ${ }^{1}$

O aumento mais intenso da taxa de desemprego para os trabalhadores com níveis mais baixos de qualificação pode, pelo menos em parte, ser explicado pelo intenso processo de incorporação de novas tecnologias que se seguiu à abertura da economia brasileira no início dos anos noventa. Como estas são tecnologias mais intensivas em trabalhadores qualificados, a demanda relativa por trabalho nãoqualificado deve ter caído ao longo do período. Como a estrutura da oferta varia mais lentamente, o resultado é mais desemprego para este grupo de trabalhadores. Porém, como este é também o segmento mais flexível do mercado de trabalho, ou seja, a legislação trabalhista é menos efetiva e têm baixa capacidade de organização sindical, a pergunta é porque os salários reais não se ajustaram para evitar este aumento da taxa de desemprego. O comportamento do rendimento médio do trabalho principal sugere que efeitos relacionados à pressão salarial devem ter tido um papel importante nesse sentido. Apesar dos trabalhadores não-qualificados terem experimentado o maior aumento na taxa de desemprego, seus rendimentos aumentaram em relação aos semi-qualificados e qualificados. O comportamento do salário mínimo poderia ter levado a esses resultados sobre o desemprego e os rendimentos. Entretanto, não se nota uma tendência clara de aumento do valor real do salário mínimo entre o final da década de oitenta e o final dos anos noventa.

Um segundo fato estilizado importante ocorrido a partir da década de noventa foi o aumento do valor da aposentadoria domiciliar per capita (ou seja, da renda da aposentadoria dos domicílios dividida pelo número de moradores destes mesmos domicílios). Este aumento foi acompanhado de forte redução do rendimento do trabalho principal. O resultado foi que a participação das aposentadorias na renda domiciliar per capita cresceu substancialmente na década de noventa.

Neste artigo, argumentamos que estes dois fenômenos estão intimamente interligados. A maior renda decorrente da aposentadoria teria aumentado o salário de reserva dos trabalhadores, ainda que os beneficios fossem recebidos por outros membros do domicílio que não os participantes da PEA, supondo que esta renda fosse distribuída entre os membros dos domicílios. O aumento do salário de reserva, por sua vez, teria gerado um aumento da pressão salarial, levando a maiores taxas de desemprego e à maior incidência de desemprego de longo prazo, definida nesse trabalho como a proporção dos desempregados com mais de um ano nesta condição. Os aumentos no salário reserva também teriam influenciado as decisões de participação dos trabalhadores. ${ }^{2}$

\footnotetext{
${ }^{1}$ Os trabalhadores são divididos em três grupos de qualificação, com base no nível de escolaridade: não-qualificados (indivíduos que não completaram o primário), semi-qualificados (definidos como os indivíduos com o segundo grau incompleto) e qualificados (com pelo menos o segundo grau completo).

${ }^{2} \mathrm{O}$ apêndice procura apresentar esse argumento com mais detalhes.
} 
Aposentadoria, Pressão Salarial e Desemprego por Nível de Qualificação

Para conciliar as evidências empíricas com o argumento proposto no artigo, os efeitos da aposentadoria sobre o comportamento dos trabalhadores devem ter sido mais fortes para os não-qualificados. Com o aumento do salário de reserva proporcionado pelas maiores aposentadorias, esses trabalhadores teriam passado a recusar ofertas de emprego consideradas insatisfatórias, que seriam aceitas com uma renda alternativa mais baixa. Conseqüentemente, se por um lado isso teria levado a aumentos nos rendimentos do trabalho principal em termos relativos, por outro, contribuiria para o aumento mais intenso do desemprego desse grupo.

O objetivo desse trabalho é investigar os possíveis impactos dos aumentos na aposentadoria domiciliar sobre a trajetória do desemprego no Brasil. Pretende-se também analisar de que forma esses efeitos foram diferenciados entre os grupos de qualificação, para ajudar a explicar os comportamentos relativos do desemprego e dos rendimentos. A análise empírica consiste em analisar os impactos da aposentadoria domiciliar sobre medidas de desemprego e de participação para o período de 1981 a 1999, usando dados da PNAD. Nessas regressões, implementadas separadamente para trabalhadores não-qualificados, semi-qualificados e qualificados, são usados dados de cross-sections repetidas para coortes de nascimento.

De acordo com os resultados, maiores aposentadorias estão diretamente relacionadas a taxas mais altas de desemprego para os trabalhadores não-qualificados. Para esses trabalhadores também são encontradas evidências de que maiores aposentadorias aumentaram a taxa de desemprego de longo prazo, assim como a proporção de desempregados de longo prazo. No caso dos semi-qualificados, algumas especificações sugerem que os aumentos das aposentadorias contribuíram para taxas mais elevadas de desemprego de longo prazo. Para os trabalhadores qualificados, no entanto, não são encontradas evidências de que as aposentadorias influenciaram o aumento do desemprego desse grupo. Os resultados também mostram que os aumentos na aposentadoria domiciliar per capita contribuíram para a redução da taxa de participação e o aumento da taxa de não-emprego, principalmente para os trabalhadores não-qualificados.

Resultados semelhantes são encontrados por Banerjee et alii (2007) para a África do Sul. Esses autores mostram evidências de que a generosidade do sistema de pensões para idosos contribuiu para o aumento significativo da taxa de desemprego a partir dos anos noventa na África do Sul. Outros trabalhos enfatizam a relação entre renda alternativa de forma geral e desemprego. Bloemen e Stancanelli (2001), também com dados para a Holanda, mostram que maiores riquezas individuais influenciam positivamente o salário de reserva e reduzem a probabilidade de emprego. Arulampalam e Stewart (1995) encontram evidências para o Reino Unido de que trabalhadores desempregados com rendas mais elevadas permanecem mais tempo no desemprego. Usando dados da PNAD de 1995, Fernandes e Picchetti (1999) mostram evidências para o Brasil de que a renda familiar líquida dos rendimentos do trabalho reduz a probabilidade de desemprego dos indivíduos. Esse resultado, porém, é contrário aos reportados na literatura internacional. Esses autores mostram também que rendas familiares mais altas aumentam a probabilidade de inatividade.

O artigo está dividido em sete seções além dessa introdução. A seção seguinte procura descrever brevemente as principais mudanças no mercado de trabalho e no sistema de aposentadorias durante as décadas de oitenta e noventa no Brasil. A terceira seção apresenta os dados utilizados no trabalho e a seção 4 descreve as trajetórias do desemprego, da participação e da aposentadoria durante as décadas de oitenta e noventa. A seção 5 apresenta as estratégias empíricas adotadas para estimar os efeitos da aposentadoria sobre o desemprego e a participação. A seção 6 contém os resultados estimados para o desemprego, e na seção 7 são apresentados os resultados para as taxas de participação e de nãoemprego. A seção 8 contém as conclusões do trabalho. 


\section{MERCADO DE TRABALHO E SISTEMA DE APOSENTADORIAS NO BRASIL: UMA BREVE DESCRIÇÃO DAS PRINCIPAIS ALTERAÇÕES NOS ANOS 80 E 90}

A década de noventa foi marcada por mudanças importantes no mercado de trabalho brasileiro. 0 processo de liberalização, iniciado em 1988, foi intensificado a partir de 1990 . Com isso, a demanda relativa por trabalho qualificado parece ter sido bastante alterada. Tecnologias mais modernas passaram a ser incorporadas ao processo produtivo com muito mais intensidade a partir da década de noventa, aumentando a demanda por trabalhadores qualificados em relação aos trabalhadores com níveis mais baixos de qualificação (Fernandes e Menezes-Filho, 2002). A maior entrada de produtos industrializados aumentou a competição no mercado interno. Além disso, durante os anos noventa, ocorreu um programa de privatizações bastante amplo, o que também deve ter contribuído para alterar a estrutura da demanda por trabalho através do aumento da competição no mercado doméstico. Outro fato importante observado durante esse período foi a alteração na composição da força de trabalho por educação, com o aumento na participação de indivíduos mais escolarizados na População Economicamente Ativa.

A legislação trabalhista também passou por modificações importantes com a aprovação da constituição de 1988, gerando uma séria de restrições ao funcionamento do mercado de trabalho (Barros et alii, 1999). Os custos das firmas com a mão-de-obra foram aumentados e a nova legislação ampliou os incentivos para os trabalhadores provocarem a própria demissão, elevando a rotatividade no mercado de trabalho (Gonzaga, 2003).

A Constituição de 1988 instituiu uma série de mudanças no sistema previdenciário brasileiro. Como resultado dessas reformas, os gastos com aposentadoria aumentaram consideravelmente nos anos noventa, principalmente pelo aumento no número de beneficiados (Giambiagi e Além, 1997, Najberg e Ikeda, 1999). Para as mulheres, o tempo de serviço necessário para a aposentadoria foi reduzido em 5 anos. A concessão de aposentadoria por idade também sofreu uma redução de 5 anos para os trabalhadores rurais em relação aos trabalhadores urbanos. Além disso, a LOAS (Lei Orgânica de Assistência Social) aboliu a necessidade de contribuição para a concessão de benefícios por idade. Trabalhadores rurais tiveram ganhos nos valores dos benefícios com a equiparação entre trabalhadores rurais e urbanos. Antes da constituição o menor benefício concedido a um trabalhador urbano era de 1 salário mínimo, enquanto o valor mínimo para um trabalhador rural era de $50 \%$ do valor do salário mínimo. Os Servidores públicos também tiveram vantagens consideráveis, já que as aposentadorias passaram a ocorrer com proventos iguais a ultima remuneração do trabalhador. Em 1998, uma nova reforma limitou a generosidade do sistema de previdência brasileiro.

\section{DADOS}

Os dados usados na análise são da PNAD (Pesquisa Nacional por Amostra de domicílios) realizada pelo IBGE (Instituto Brasileiro de Geografia e Estatística). A amostra utilizada inclui todos os indivíduos entre 25 e 59 anos, residentes nas áreas urbanas. São usados dados para todos os anos de 1981 a 1999 , exceto 1991 e 1994 quando a pesquisa não foi realizada.

Para cada indivíduo são coletadas informações sobre as suas características, como idade, escolaridade, região de residência e gênero, além de dados sobre o rendimento médio do trabalho principal. Para esses indivíduos, também são obtidas informações sobre a participação na População Economicamente Ativa (PEA). Utilizando a semana como período de referência, os trabalhadores pertencentes a PEA são classificados como empregados ou desempregados. A PNAD permite que entre os indivíduos desempregados sejam identificados aqueles há mais de 1 ano sem emprego, embora não existam informações sobre a busca por emprego dessas pessoas, ou seja, se estiveram o período todo desempregados ou se passaram parte do tempo fora da força de trabalho. Esses trabalhadores desempregados na semana de referência que não tinham emprego há mais de um ano são classificados como desempregados de longo 
prazo. $^{3}$

Para definir o nível de qualificação é usado o número máximo de anos de estudo completado por cada indivíduo. São classificados como não-qualificados os trabalhadores com até o primário incompleto (entre 0 e 3 anos de estudo), como semi-qualificados aqueles com até o segundo grau incompleto (entre 4 e 10 anos de estudo) e como qualificados os indivíduos que pelo menos completaram o segundo grau (11 anos ou mais de estudo).

Algumas variáveis são construídas para os domicílios. Nesse caso, são incluídos todos os indivíduos residindo em domicílios ocupados por pessoas entre 25 e 59 anos, nas áreas urbanas. A aposentadoria domiciliar per capita é calculada através da razão entre o total da renda com aposentadoria em cada domicílio e o número de pessoas nesse domicílio. Para esses domicílios também são calculadas a renda domiciliar per capita total, o número de crianças com 10 anos ou menos, a escolaridade média dos adultos com 18 anos ou mais, a situação dos aposentados no mercado de trabalho, e a relação de parentesco entre o aposentado e o participante da PEA.

$\mathrm{Na}$ análise empírica também são utilizadas algumas variáveis macroeconômicas, como o PIB e a inflação. O PIB é o calculado pelo IBGE e a taxa de inflação é a fornecida pelo INPC, que é calculado todo mês, também pelo IBGE, com um período de coleta que vai do dia 1 ao dia 30 de cada mês. A variável utilizada nas regressões é o INPC do mês de setembro de cada ano, que é o período em que é realizada a PNAD.

\section{ANÁLISE DESCRITIVA}

Esta seção descreve os comportamentos do desemprego, da renda de aposentadoria e da taxa de participação, durante as décadas de 80 e 90. Essas análises são implementadas tanto em termos agregados como para cada nível de qualificação separadamente, procurando identificar diferenças nas trajetórias entre esses grupos.

\subsection{Desemprego}

A tabela 1 apresenta dados relativos ao desemprego agregado entre 1981 e 1999 . Nota-se, pela primeira coluna, que durante a década de noventa ocorreu um grande aumento na taxa desemprego, que passou de 3,12\% em 1990 para 8,58\% em 1999. Como mostra a segunda coluna, também a partir de 1990, aumenta substancialmente o desemprego de longo prazo. A taxa de desemprego de longo prazo passou de 0,97\% em 1990 para 4,48\% em 1999. Entre 1990 e 1999 a porcentagem dos desempregados que estavam sem emprego há um ano ou mais aumentou de $31 \%$ para $52 \%$. Contrastando com essas evidências para os anos noventa, na década anterior não se nota qualquer tendência específica para essas três variáveis.

As trajetórias das variáveis de desemprego para cada nível de qualificação são apresentadas na tabela 2. Apesar da taxa de desemprego ter aumentado para todos os grupos na década de noventa, a variação foi mais acentuada para os não-qualificados (6,64 pontos percentuais entre 1990 e 1999). Os aumentos para os semi-qualificados e os qualificados, nesse mesmo intervalo de tempo, foram de 5,71 e 4,43 pontos percentuais, respectivamente.

O aumento da taxa de desemprego de longo prazo também foi decrescente com o nível de qualificação. Para os não-qualificados foi registrado um aumento de 0,73\% para 4,42\% entre 1990 e 1999 , enquanto para os semi-qualificados a taxa de desemprego de longo prazo aumentou de $1,15 \%$ para

\footnotetext{
${ }^{3}$ Embora o critério de um ano seja o mais utilizado para definir desemprego de longo prazo, essa classificação é diferente da usada normalmente na literatura, em que os indivíduos desempregados são perguntados há quanto tempo estão procurando emprego. É importante destacar que também existem problemas com variáveis desse tipo pelo alto grau de erros de medida e pelo fato de um único dia fora do desemprego fazer com que a duração do desemprego volte a ser zero (Machin e Manning, 1999).
} 
Tabela 1 - Taxas de Desemprego (\%) - 1981:1999

\begin{tabular}{|c|c|c|c|}
\hline Ano & Taxa de desemprego & $\begin{array}{c}\text { Taxa de desemprego de } \\
\text { longo prazo }\end{array}$ & $\begin{array}{c}\text { Desempregados há mais de } \\
\text { um ano sem emprego }\end{array}$ \\
\hline 81 & $(1)$ & $(2)$ & $(3)$ \\
82 & 3,35 & 1,05 & 31,39 \\
83 & 3,01 & 0,87 & 28,94 \\
84 & 4,23 & 1,22 & 28,85 \\
85 & 3,37 & 1,22 & 36,08 \\
86 & 2,67 & 0,98 & 36,75 \\
87 & 1,82 & 0,62 & 33,92 \\
88 & 2,80 & 0,79 & 28,14 \\
89 & 2,95 & 1,00 & 33,83 \\
90 & 2,49 & 0,79 & 31,90 \\
92 & 3,12 & 0,97 & 31,13 \\
93 & 5,94 & 2,39 & 40,24 \\
95 & 5,48 & 2,39 & 43,60 \\
96 & 5,31 & 2,04 & 38,35 \\
97 & 6,18 & 2,81 & 45,46 \\
98 & 6,90 & 3,11 & 45,06 \\
99 & 7,70 & 3,89 & 50,44 \\
$\Delta(99-81)$ & 8,58 & 4,48 & 52,22 \\
$\Delta(99-90)$ & 5,23 & 3,43 & 20,83 \\
\hline
\end{tabular}

Fonte: PNAD. A amostra é formada pelos indivíduos residentes nas áreas urbanas entre 25 e 59 anos que participam da PEA.

Os desempregados de longo prazo são definidos como os indivíduos desempregados na semana de referência sem emprego há pelo menos 1 ano.

Tabela 2 - Taxas de Desemprego por Qualificação (\%) - 1981:1999

\begin{tabular}{|c|c|c|c|c|c|c|c|c|c|}
\hline & \multicolumn{3}{|c|}{$\begin{array}{c}\text { Taxa de desemprego } \\
\text { desemprego }\end{array}$} & \multicolumn{3}{|c|}{$\begin{array}{c}\text { Taxa de desemprego de } \\
\text { de longo prazo }\end{array}$} & \multicolumn{3}{|c|}{$\begin{array}{c}\text { Desempregados há mais de } \\
\text { um ano sem emprego }\end{array}$} \\
\hline & \begin{tabular}{|c|} 
Não- \\
qualificados
\end{tabular} & \begin{tabular}{|c|} 
Semi- \\
qualificados
\end{tabular} & Qualificados & \begin{tabular}{|c|} 
Não- \\
qualificados
\end{tabular} & \begin{tabular}{|c|} 
Semi- \\
qualificados
\end{tabular} & Qualificados & \begin{tabular}{|c|} 
Não- \\
qualificados
\end{tabular} & \begin{tabular}{|c|} 
Semi- \\
qualificados
\end{tabular} & Qualificados \\
\hline Ano & $(1)$ & $(2)$ & (3) & (4) & $(5)$ & (6) & $(7)$ & $(8)$ & (9) \\
\hline 81 & 3,47 & 3,68 & 2,43 & 0,83 & 1,12 & 1,25 & 23,96 & 30,41 & 51,43 \\
\hline 82 & 2,80 & 3,60 & 2,19 & 0,61 & 0,97 & 1,10 & 21,68 & 27,06 & 50,11 \\
\hline 83 & 4,01 & 4,90 & 3,32 & 0,87 & 1,38 & 1,44 & 21,69 & 28,12 & 43,33 \\
\hline 84 & 3,12 & 3,98 & 2,58 & 0,84 & 1,45 & 1,29 & 27,06 & 36,52 & 49,88 \\
\hline 85 & 2,31 & 3,19 & 2,19 & 0,64 & 1,08 & 1,23 & 27,72 & 33,77 & 56,34 \\
\hline 86 & 1,57 & 2,06 & 1,70 & 0,43 & 0,63 & 0,81 & 27,70 & 30,64 & 47,45 \\
\hline 87 & 2,59 & 3,24 & 2,28 & 0,57 & 0,88 & 0,86 & 22,21 & 27,27 & 37,58 \\
\hline 88 & 2,92 & 3,35 & 2,34 & 0,73 & 1,07 & 1,15 & 24,95 & 32,00 & 49,31 \\
\hline 89 & 2,48 & 2,94 & 1,78 & 0,63 & 0,86 & 0,84 & 25,63 & 29,17 & 47,43 \\
\hline 90 & 2,95 & 3,69 & 2,38 & 0,73 & 1,15 & 0,91 & 24,84 & 31,01 & 38,42 \\
\hline 92 & 6,30 & 6,58 & 4,65 & 2,12 & 2,58 & 2,35 & 33,60 & 39,29 & 50,59 \\
\hline 93 & 5,70 & 6,23 & 4,08 & 2,14 & 2,66 & 2,16 & 37,45 & 42,79 & 52,93 \\
\hline 95 & 5,81 & 5,83 & 4,07 & 1,86 & 2,15 & 2,00 & 32,01 & 36,81 & 49,06 \\
\hline 96 & 7,00 & 6,87 & 4,56 & 2,76 & 3,06 & 2,47 & 39,42 & 44,50 & 54,23 \\
\hline 97 & 7,50 & 7,78 & 5,28 & 3,12 & 3,39 & 2,71 & 41,66 & 43,59 & 51,37 \\
\hline 98 & 8,35 & 8,68 & 5,96 & 3,65 & 4,32 & 3,45 & 43,74 & 49,71 & 57,83 \\
\hline 99 & 9,59 & 9,40 & 6,81 & 4,42 & 4,78 & 4,08 & 46,11 & 50,88 & 59,97 \\
\hline \begin{tabular}{|l|}
$\Delta(99-81)$ \\
\end{tabular} & 6,11 & 5,72 & 4,38 & 3,59 & 3,66 & 2,84 & 22,15 & 20,47 & 8,54 \\
\hline$\Delta(99-90)$ & 6,64 & 5,71 & 4,43 & 3,69 & 3,64 & 3,17 & 21,27 & 19,86 & 21,55 \\
\hline
\end{tabular}

Fonte: PNAD. A amostra é formada pelos indivíduos residentes nas áreas urbanas entre 25 e 59 anos que participam da PEA.

Os desempregados de longo prazo são definidos como os indivíduos desempregados na semana de referência sem emprego há pelo menos 1 ano. 
Aposentadoria, Pressão Salarial e Desemprego por Nível de Qualificação

$4,78 \%$ e para os qualificados de $0,91 \%$ para $4,08 \%$. A proporção de desempregados sem emprego há mais de um ano também aumentou para os três grupos, mas as variações foram semelhantes. A proporção entre os não-qualificados aumentou em 21 pontos percentuais, e entre os semi-qualificados e qualificados os aumentos foram, respectivamente, de 20 e 22 pontos percentuais. Em 1999, 46\% dos não-qualificados, $51 \%$ dos semi-qualificados e $60 \%$ dos qualificados desempregados estavam na condição de não-empregados há pelo menos um ano. Como no caso das taxas agregadas, a tendência de aumento para essas variáveis é iniciada na década de noventa, enquanto nos anos oitenta, são observadas apenas flutuações cíclicas.

Embora tenha ocorrido uma mudança metodológica na pesquisa a partir de 1992, a trajetória do desemprego na PNAD é semelhante à observada nos dados da PME (Pesquisa mensal de Emprego) durante o início da década de noventa. ${ }^{4}$ De qualquer forma, as conclusões principais descritas nessa subseção não seriam alteradas se o final da década de oitenta fosse usado como referência ao invés de 1990 . Os dados mostram que a partir de 1988 ou 1989 a taxa de desemprego aumentou bastante no Brasil, principalmente para os trabalhadores com níveis mais baixos de qualificação.

\subsection{Aposentadoria e Renda Domiciliar per Capita}

Esta subseção descreve os comportamentos da aposentadoria e da renda domiciliar ao longo das décadas de oitenta e noventa. Como a tabela 3 mostra, a renda domiciliar per capita advinda de aposentadoria (que daremos o nome de aposentadoria domiciliar per capita), aumentou a partir de 1990 para os indivíduos entre 25 e 59 anos que participavam da PEA, tanto para o conjunto dos indivíduos, quanto se os indivíduos forem divididos por seu nível de qualificação. Entre 1990 e 1999 essa variável aumentou no total de R\$ 15,6 em 1990 para R\$ 24,9 em 1999..$^{5} \mathrm{Em}$ todos os grupos de qualificação são observadas trajetórias de aumento na aposentadoria domiciliar per capita durante os anos noventa. Para os não-qualificados foi registrado um aumento de R\$ 4,7 para R\$ 9,3 entre 1990 e 1999, e para os semi-qualificados e qualificados as variações nesse mesmo período foram de $\mathrm{R} \$ 9,7$ para $\mathrm{R} \$ 14,1$ e de R\$ 34,7 para R\$ 49,2, respectivamente. ${ }^{6}$ A variação percentual foi maior para os não-qualificados (quase $100 \%$ ), enquanto para os outros dois grupos os aumentos foram em torno de $40 \%$. Entretanto, usando 1988 como base, ou seja analisando o período 1988 a 1999, a variação para os qualificados foi semelhante a dos não-qualificados.

Na tabela 4 são mostrados os valores médios das aposentadorias para cada um dos grupos de qualificação. Esses valores são calculados para todos os indivíduos que recebem alguma renda de aposentadoria, independentemente da idade e da participação no mercado de trabalho. Para os não-qualificados a aposentadoria média em 1999 é praticamente a mesma de 1981. Nesse mesmo período, os valores médios das aposentadorias diminuíram para os indivíduos semi-qualificados e qualificados em $17 \%$ e $9 \%$, respectivamente. Considerando apenas a década de noventa, as aposentadorias aumentaram para os não-qualificados (34\%), e diminuíram ligeiramente para os qualificados $(8 \%)$, permanecendo estáveis para os semi-qualificados.

A tabela 4 mostra também que a proporção de indivíduos com 25 anos ou mais recebendo aposentadoria aumentou continuamente entre 81 e 99 , resultado fortemente influenciado pelas mudanças demográficas, já que ocorreu um envelhecimento da população nesse período. Nota-se que os aumentos

\footnotetext{
${ }^{4} \mathrm{Na}$ década de oitenta trabalhadores não-remunerados que trabalhavam menos de 15 horas na semana não eram considerados empregados. Caso estivessem procurando emprego esses trabalhadores eram classificados como desempregados. Trabalhadores ocupados em atividades para o próprio consumo ou na construção para o próprio uso não eram considerados empregados na década de oitenta. Para compatibilizar as duas versões, na década de noventa foram considerados os mesmos critérios das PNADs da década de oitenta para classificar a condição de ocupação dos trabalhadores. Além disso, também ocorreu uma mudança na ordem das perguntas no questionário.

${ }^{5}$ Valores em Reais de 1999.

${ }^{6}$ Deve-se notar que esses valores são médias para toda a amostra de domicílios com pessoas na PEA, com idade entre 25 e 59 anos. Muitos desses domicílios não possuem indivíduos recebendo aposentadoria.
} 
mais acentuados se verificaram na década de noventa, e que foram maiores para os não-qualificados. Enquanto esse grupo aumentou em 5 pontos percentuais a porcentagem de indivíduos com renda de aposentadoria, entre os semi-qualificados e os qualificados os aumentos foram de 2 e 3.8 pontos percentuais, respectivamente. Portanto, para os não-qualificados ocorreram aumentos tanto no valor médio das aposentadorias quanto na proporção de indivíduos recebendo esse benefício. Para os semiqualificados e qualificados os aumentos ocorreram basicamente devido à maior proporção de pessoas recebendo aposentadoria. ${ }^{7}$

Tabela 3 - Aposentadoria Domiciliar per Capita* (para os domicílios com indivíduos entre 25 e 59 anos na PEA - em R\$ de 1999)

\begin{tabular}{|c|c|c|c|c|}
\hline & Não-qualificados & Semi-qualificados & Qualificados & Total \\
\hline Ano & $(1)$ & $(2)$ & $(3)$ & $(4)$ \\
\hline 81 & 5,74 & 11,95 & 35,14 & 14,80 \\
82 & 5,62 & 12,03 & 33,22 & 14,40 \\
83 & 4,46 & 10,09 & 30,61 & 12,94 \\
84 & 4,66 & 9,66 & 27,25 & 12,16 \\
85 & 5,23 & 10,36 & 32,85 & 14,37 \\
86 & 7,11 & 13,18 & 44,89 & 19,53 \\
87 & 4,65 & 10,22 & 31,64 & 14,25 \\
88 & 5,28 & 9,39 & 28,16 & 13,42 \\
89 & 5,06 & 10,74 & 34,35 & 15,87 \\
90 & 4,74 & 9,69 & 34,70 & 15,63 \\
92 & 6,33 & 9,48 & 31,22 & 14,86 \\
93 & 6,58 & 9,97 & 32,55 & 15,68 \\
95 & 7,33 & 11,86 & 41,34 & 19,57 \\
96 & 7,69 & 12,41 & 43,18 & 20,94 \\
97 & 8,15 & 12,40 & 44,19 & 21,76 \\
98 & 8,67 & 14,32 & 48,80 & 24,57 \\
99 & 9,29 & 14,07 & 49,15 & 24,90 \\
\hline$\Delta \%(99-81)$ & 62,0 & 17,7 & 39,9 & 68,3 \\
$\Delta \%(90-81)$ & $-17,3$ & $-18,9$ & $-1,3$ & 5,6 \\
$\Delta \%(99-90)$ & 95,8 & 45,2 & 41,7 & 59,4 \\
\hline
\end{tabular}

Fonte: PNAD. A amostra é formada pelos indivíduos residentes nas áreas urbanas entre 25 e 59 anos que participam da PEA.

* A aposentadoria domiciliar per capita é a razão entre a soma das aposentadorias recebidas por todos os membros da família no domicílio e o número de pessoas no domicílio.

Para analisar a evolução das características das pessoas que receberam renda de aposentadoria entre 1981 e 1999, são definidas na tabela 5 três categorias: indivíduos entre 25 e 59 anos que participam da PEA, indivíduos nessa mesma faixa de idade que não participam da PEA e pessoas com 60 anos ou mais. No primeiro desses grupos as proporções dos que receberam aposentadoria são muito pequenas nos três níveis de qualificação. Embora tenham ocorrido aumentos ao longo do tempo, as magnitudes dessas variações também são relativamente baixas.

Para os indivíduos entre 25 e 59 anos que não participam da PEA as proporções dos que receberam aposentadoria aumentaram para os três grupos de qualificação durante a década de noventa, mas principalmente para os qualificados. Não-qualificados experimentaram um aumento de 1,6 ponto percentual, semi-qualificados de 2 pontos percentuais e qualificados um aumento bem maior, de 7,8 pontos percentuais, passando de $15,7 \%$ para $23,5 \%$ entre 1990 e 1999. Este resultado parece indicar que entre os trabalhadores qualificados, o aumento da porcentagem de pessoas recebendo aposentadorias pode

\footnotetext{
${ }^{7}$ Não se pode fazer uma relação direta entre os resultados das tabela 3 e 4 pelo fato de que em um mesmo domicílio os indivíduos podem apresentar qualificações diferentes e, por exemplo, a aposentadoria domiciliar per capita de um indivíduo qualificado ser proveniente da aposentadoria recebida por um não-qualificado.
} 
ter levado a uma redução da taxa de participação na força de trabalho, efeito este que não parece ser verdadeiro para os não qualificados.

Tabela 4 - Aposentadoria (valor médio e porcentagem dos indivíduos que recebem renda de aposentadoria)

\begin{tabular}{|c|c|c|c|c|c|c|}
\hline & \multicolumn{3}{|c|}{$\begin{array}{c}\text { Valor médio das aposentadorias } \\
\text { (R\$ de 1999) }\end{array}$} & \multicolumn{3}{|c|}{$\begin{array}{c}\text { Indivíduos com renda de } \\
\text { aposentadoria (\%) }\end{array}$} \\
\hline & Não- & Semi- & Qualificados & Não- & Semi- & Qualificados \\
\hline Ano & $(1)$ & $(2)$ & $(3)$ & $(4)$ & $(5)$ & $(6)$ \\
\hline 81 & 192 & 510 & 1363 & 17,4 & 9,6 & 6,8 \\
82 & 192 & 521 & 1495 & 17,6 & 9,5 & 7,1 \\
83 & 173 & 463 & 1219 & 15,6 & 9,6 & 7,6 \\
84 & 162 & 418 & 1189 & 18,3 & 9,9 & 7,4 \\
85 & 176 & 477 & 1369 & 18,8 & 10,0 & 7,7 \\
86 & 214 & 551 & 1783 & 19,6 & 10,6 & 7,9 \\
87 & 137 & 387 & 1310 & 19,3 & 10,2 & 7,8 \\
88 & 144 & 389 & 1212 & 20,0 & 10,1 & 7,8 \\
89 & 162 & 466 & 1355 & 20,2 & 10,1 & 8,0 \\
90 & 147 & 431 & 1343 & 20,5 & 10,2 & 8,0 \\
92 & 201 & 424 & 1056 & 19,9 & 9,6 & 8,6 \\
93 & 190 & 407 & 1113 & 22,2 & 10,2 & 8,9 \\
95 & 195 & 420 & 1309 & 22,7 & 10,7 & 10,1 \\
96 & 185 & 419 & 1225 & 24,2 & 11,3 & 10,7 \\
97 & 189 & 409 & 1234 & 23,9 & 11,6 & 11,1 \\
98 & 202 & 447 & 1235 & 24,4 & 12,1 & 11,9 \\
99 & 197 & 424 & 1238 & 25,5 & 12,2 & 11,8 \\
\hline$\%$ (99-81) & 2,6 & $-17,0$ & $-9,1$ & 45,9 & 27,7 & 73,2 \\
$\Delta \%$ (90-81) & $-23,6$ & $-15,5$ & $-1,4$ & 17,5 & 6,5 & 16,8 \\
$\Delta \%$ (99-90) & 34,3 & $-1,8$ & $-7,8$ & 24,1 & 20,0 & 48,3 \\
\hline
\end{tabular}

Fonte: PNAD. A amostra é formada pelos indivíduos residentes nas áreas urbanas com mais de 25 anos. As médias são calculadas apenas para pessoas que recebem alguma renda de aposentadoria.

Os maiores aumentos na proporção de pessoas que receberam aposentadoria foram verificados para aqueles com 60 anos ou mais. Não-qualificados registraram um aumento de 6,4 pontos percentuais entre 1990 e 1999, após um aumento de apenas 2 pontos percentuais na década anterior. Para os semi-qualificados as proporções de pessoas nesse grupo recebendo aposentadoria aumentou 3,9 pontos percentuais na década de oitenta e 5,5 na década de noventa, enquanto para os qualificados as variações nessas duas décadas foram de 5,5 e 8,3 pontos percentuais, respectivamente.

O rendimento médio do trabalho principal diminuiu entre 1981 e 1999, na década de oitenta a queda foi de $8,6 \%$ e na década de noventa a redução foi de $13,4 \%$. Os três grupos de qualificação apresentaram tendências muito semelhantes durante a década de oitenta, com os rendimentos diminuindo em torno de $18 \%$. Na década de noventa, no entanto, as diferenças no comportamento dessa variável foram mais marcantes. As menores reduções ocorreram para os não-qualificados, 15,9\%, e as maiores para os semiqualificados, $22,2 \%$. O rendimento médio do trabalho principal dos trabalhadores qualificados diminuiu $18 \%$ nos anos noventa.

Com o aumento da aposentadoria domiciliar per capita e a queda dos rendimentos, a participação da aposentadoria na renda domiciliar per capita aumentou consideravelmente na década de noventa. Entre 1990 e 1999 a participação da aposentadoria aumentou de 3,1\% para 6,5\% da renda domiciliar per capita para os indivíduos não-qualificados. No caso dos semi-qualificados, a participação da aposentadoria durante esse período aumentou de $3,4 \%$ para $5,9 \%$, enquanto para os qualificados ocorreu um aumento de $4,1 \%$ para $7 \%$. 
Tabela 5 - Porcentagem que recebe Aposentadoria em Grupos de Idade e Participação na PEA

\begin{tabular}{|c|c|c|c|c|c|c|c|c|c|}
\hline & \multicolumn{3}{|c|}{$\begin{array}{c}\text { Indivíduos entre } 25 \text { e } 59 \text { anos } \\
\text { na PEA }\end{array}$} & \multicolumn{3}{|c|}{$\begin{array}{c}\text { Indivíduos entre } 25 \text { e } 59 \text { anos que } \\
\text { não participam da PEA }\end{array}$} & \multicolumn{3}{|c|}{$\begin{array}{l}\text { Indivíduos com } 60 \text { anos } \\
\text { ou mais }\end{array}$} \\
\hline & \begin{tabular}{|c|} 
Não- \\
qualificados
\end{tabular} & \begin{tabular}{|c|} 
Semi- \\
qualificados
\end{tabular} & Qualificados & \begin{tabular}{|c|} 
Não- \\
qualificados
\end{tabular} & \begin{tabular}{|c|} 
Semi- \\
qualificados
\end{tabular} & Qualificados & \begin{tabular}{|c|} 
Não- \\
qualificados
\end{tabular} & \begin{tabular}{|c|} 
Semi- \\
qualificados
\end{tabular} & Qualificados \\
\hline Ano & $(1)$ & $(2)$ & (3) & (4) & (5) & (6) & (7) & (8) & (9) \\
\hline 81 & 2,1 & 2,1 & 1,8 & 12,3 & 10,9 & 11,8 & 53,7 & 48,7 & 60,5 \\
\hline 82 & 2,2 & 2,0 & 1,6 & 12,0 & 10,9 & 12,3 & 55,1 & 49,4 & 64,3 \\
\hline 83 & 1,9 & 2,1 & 1,9 & 11,1 & 10,8 & 15,2 & 47,8 & 49,0 & 63,1 \\
\hline 84 & 1,9 & 1,9 & 1,9 & 12,8 & 11,4 & 14,7 & 54,8 & 52,2 & 66,3 \\
\hline 85 & 2,3 & 1,9 & 1,9 & 12,6 & 11,7 & 16,2 & 55,8 & 51,6 & 67,7 \\
\hline 86 & 2,6 & 2,1 & 2,0 & 12,7 & 11,8 & 15,9 & 56,5 & 54,4 & 67,4 \\
\hline 87 & 2,5 & 2,5 & 2,0 & 12,5 & 10,4 & 15,5 & 55,3 & 53,8 & 65,2 \\
\hline 88 & 3,0 & 2,2 & 1,9 & 12,2 & 10,5 & 16,0 & 55,7 & 54,3 & 66,4 \\
\hline 89 & 2,4 & 2,1 & 2,0 & 13,1 & 10,7 & 15,5 & 55,1 & 52,8 & 66,4 \\
\hline 90 & 2,4 & 2,1 & 2,1 & 12,4 & 10,4 & 15,7 & 55,7 & 52,6 & 66,0 \\
\hline 92 & 2,0 & 1,8 & 2,3 & 11,7 & 9,7 & 16,8 & 55,7 & 55,7 & 69,2 \\
\hline 93 & 2,5 & 1,9 & 2,4 & 13,4 & 10,4 & 18,5 & 59,1 & 56,7 & 70,5 \\
\hline 95 & 2,4 & 2,4 & 3,0 & 12,4 & 10,4 & 20,6 & 60,5 & 57,5 & 72,2 \\
\hline 96 & 2,7 & 2,6 & 3,4 & 13,0 & 10,4 & 20,6 & 62,3 & 58,2 & 72,8 \\
\hline 97 & 2,8 & 2,7 & 3,7 & 13,3 & 10,9 & 22,8 & 60,8 & 58,8 & 72,3 \\
\hline 98 & 2,7 & 3,0 & 4,1 & 13,8 & 12,1 & 23,7 & 61,0 & 57,7 & 74,0 \\
\hline 99 & 2,8 & 2,9 & 3,9 & 14,0 & 12,4 & 23,5 & 62,1 & 58,1 & 74,3 \\
\hline$\Delta(99-81)$ & 0,67 & 0,80 & 2,07 & 1,71 & 1,42 & 11,75 & 8,48 & 9,40 & 13,82 \\
\hline$\Delta(90-81)$ & 0,35 & $-0,01$ & 0,33 & 0,14 & $-0,58$ & 3,90 & 2,08 & 3,87 & 5,46 \\
\hline$\Delta(99-90)$ & 0,33 & 0,81 & 1,75 & 1,57 & 2,00 & 7,85 & 6,40 & 5,53 & 8,35 \\
\hline
\end{tabular}

Fonte: PNAD. A amostra é formada pelos indivíduos residentes nas áreas urbanas com mais de 25 anos.

Tabela 6 - Rendimento Médio do Trabalho Principal e Participação da Aposentadoria na Renda Domiciliar

\begin{tabular}{|c|c|c|c|c|c|c|c|c|}
\hline & \multicolumn{4}{|c|}{$\begin{array}{l}\text { Rendimento médio do } \\
\text { trabalho principal (RS de 1999) }\end{array}$} & \multicolumn{4}{|c|}{$\begin{array}{l}\text { Participação da aposentadoria na } \\
\text { renda domiciliar per capita (\%) }\end{array}$} \\
\hline & \begin{tabular}{|c|} 
Não- \\
qualificados
\end{tabular} & $\begin{array}{c}\text { Semi- } \\
\text { qualificados }\end{array}$ & Qualificados & Total & \begin{tabular}{|c|} 
Não- \\
qualificados
\end{tabular} & \begin{tabular}{|c|} 
Semi- \\
qualificados
\end{tabular} & Qualificados & Total \\
\hline Ano & (1) & (2) & (3) & (4) & (5) & (6) & (7) & (8) \\
\hline 81 & 353,0 & 630,1 & 1544,6 & 731 & 3,3 & 3,6 & 3,6 & 3,5 \\
\hline 82 & 343,2 & 630,9 & 1554,4 & 731 & 3,3 & 3,6 & 3,3 & 3,4 \\
\hline 83 & 278,7 & 508,6 & 1235,8 & 599 & 3,2 & 3,7 & 3,8 & 3,7 \\
\hline 84 & 272,8 & 492,1 & 1198,9 & 587 & 3,5 & 3,7 & 3,5 & 3,5 \\
\hline 85 & 307,2 & 562,1 & 1393,3 & 690 & 3,3 & 3,4 & 3,5 & 3,5 \\
\hline 86 & 480,2 & 821,5 & 1935,0 & 1007 & 2,9 & 3,0 & 3,5 & 3,2 \\
\hline 87 & 335,5 & 567,6 & 1417,2 & 724 & 2,6 & 3,2 & 3,3 & 3,2 \\
\hline 88 & 281,0 & 513,8 & 1355,0 & 681 & 3,5 & 3,3 & 3,1 & 3,2 \\
\hline 89 & 320,0 & 576,9 & 1454,1 & 755 & 3,0 & 3,4 & 3,5 & 3,4 \\
\hline 90 & 287,2 & 513,5 & 1253,1 & 668 & 3,1 & 3,4 & 4,1 & 3,7 \\
\hline 92 & 239,4 & 408,1 & 948,1 & 518 & 4,9 & 4,4 & 5,3 & 5,0 \\
\hline 93 & 233,7 & 399,1 & 1018,1 & 538 & 5,2 & 4,6 & 5,1 & 4,9 \\
\hline 95 & 277,2 & 480,1 & 1221,2 & 653 & 4,8 & 4,5 & 5,1 & 4,9 \\
\hline 96 & 289,5 & 487,3 & 1197,2 & 664 & 4,8 & 4,6 & 5,5 & 5,2 \\
\hline 97 & 277,3 & 460,4 & 1177,5 & 652 & 5,2 & 4,7 & 5,7 & 5,4 \\
\hline 98 & 263,5 & 435,0 & 1141,3 & 633 & 5,7 & 5,7 & 6,3 & 6,1 \\
\hline 99 & 241,6 & 399,3 & 1027,2 & 579 & 6,5 & 5,9 & 7,0 & 6,7 \\
\hline$\Delta \%(99-81)$ & $-31,6$ & $-36,6$ & $-33,5$ & $-20,9$ & 95,2 & 64,8 & 96,5 & 87,8 \\
\hline$\Delta \%(90-81)$ & $-18,6$ & $-18,5$ & $-18,9$ & $-8,6$ & $-7,4$ & $-6,2$ & 13,3 & 5,6 \\
\hline$\Delta \%(99-90)$ & $-15,9$ & $-22,2$ & $-18,0$ & $-13,4$ & 110,9 & 75,8 & 73,4 & 77,8 \\
\hline
\end{tabular}

Fonte: PNAD. A amostra é formada pelos indivíduos residentes nas áreas urbanas entre 25 e 59 anos que participam da PEA 


\subsection{Taxa de Participação}

Entre 1981 e 1999 a taxa de participação na força de trabalho dos indivíduos entre 25 e 59 anos aumentou de $65 \%$ para $75 \%$, como a tabela 7 mostra. Esse aumento foi distribuído igualmente entre as décadas de oitenta e noventa. Aumentos na taxa de participação também foram observados para os três grupos de qualificação separadamente ${ }^{8}$. A taxa de participação dos não-qualificados aumentou 8 pontos percentuais entre 1981 e 1999, enquanto para os semi-qualificados e os qualificados os aumentos foram de 8.5 e 2 pontos percentuais, respectivamente.

Tabela 7 - Taxa de Participação por Qualificação (\%) - 1981: 1999

\begin{tabular}{|c|c|c|c|c|}
\hline & $\begin{array}{c}\text { Não- } \\
\text { qualificados }\end{array}$ & $\begin{array}{c}\text { Semi- } \\
\text { qualificados }\end{array}$ & Qualificados & Total \\
\hline Ano & $(1)$ & $(2)$ & $(3)$ & $(4)$ \\
\hline 81 & 57,36 & 64,91 & 81,60 & 64,92 \\
82 & 59,64 & 65,99 & 82,52 & 66,46 \\
83 & 59,37 & 65,61 & 82,07 & 66,37 \\
84 & 59,36 & 66,17 & 82,14 & 66,77 \\
85 & 60,20 & 66,88 & 82,73 & 67,86 \\
86 & 59,71 & 67,37 & 83,07 & 68,10 \\
87 & 61,85 & 68,60 & 82,85 & 69,51 \\
88 & 62,06 & 68,40 & 83,02 & 69,83 \\
89 & 61,18 & 68,94 & 82,91 & 69,78 \\
90 & 62,57 & 68,87 & 82,05 & 70,30 \\
92 & 63,80 & 71,05 & 83,57 & 72,06 \\
93 & 63,44 & 71,28 & 83,70 & 72,23 \\
95 & 64,58 & 72,87 & 84,17 & 73,52 \\
96 & 62,90 & 71,48 & 83,22 & 72,46 \\
97 & 63,62 & 72,10 & 84,08 & 73,40 \\
98 & 63,94 & 72,23 & 83,86 & 73,61 \\
99 & 65,35 & 73,43 & 83,50 & 74,58 \\
\hline$\Delta(99-81)$ & 8,00 & 8,52 & 1,91 & 9,66 \\
$\Delta$ (90 -81) & 5,21 & 3,96 & 0,45 & 5,38 \\
$\Delta$ (99-90) & 2,79 & 4,55 & 1,45 & 4,28 \\
\hline Fonte: PNAD. A amostra é formada pelos indivídus residentes nas áreas urbanas entre $25 e$
\end{tabular}

Fonte: PNAD. A amostra é formada pelos indivíduos residentes nas áreas urbanas entre $25 \mathrm{e}$ 59 anos.

Outro fato que pode ser verificado pela tabela 7 , é que os aumentos na taxa de participação dos semi-qualificados e qualificados foram maiores na década de noventa do que na década de oitenta. Por outro lado, a maior parte da variação na participação dos não-qualificados ocorreu durante a década de oitenta. Portanto, o ritmo de crescimento na taxa de participação de trabalhadores não-qualificados na força de trabalho diminuiu na década de noventa.

Portanto, de acordo com as evidências apresentadas nessa seção, a aposentadoria domiciliar per capita aumentou nos domicílios ocupados por indivíduos entre 25 e 59 anos, participando da força de trabalho. Com a redução no rendimento médio do trabalho principal, a importância da aposentadoria na renda domiciliar per capita foi bastante ampliada durante a década de noventa. Durante esse período também ocorreram aumentos substanciais na taxa de desemprego e no desemprego de longo prazo, principalmente para os trabalhadores não-qualificados. As evidências também mostram que a taxa de participação dos trabalhadores não-qualificados apresentou um crescimento mais baixo durante a década de noventa.

Na seção 6 são apresentados os resultados empíricos procurando avaliar o papel desempenhado por estas variações na aposentadoria para as trajetórias do desemprego de cada grupo de qualificação. A

\footnotetext{
${ }^{8}$ As tabelas 1 e 2 do apêndice mostram que esse aumento foi influenciado, nos três grupos de qualificação, pelo comportamento das mulheres. A taxa de participação dos homens diminuiu durante os anos 80 e 90 .
} 
seção 7 mostra os resultados estimados para os efeitos da aposentadoria sobre a taxa de participação e o não-emprego.

\section{METODOLOGIA}

A análise empírica implementada para investigar o impacto das aposentadorias sobre o desemprego, a participação e o não-emprego é baseada em informações de cross-sections repetidas para 17 edições da PNAD. Os dados da PNAD não permitem que os mesmos indivíduos sejam seguidos ao longo do tempo. No entanto, pode-se seguir coortes definidas por algumas características pelas quais os indivíduos podem ser identificados. Então, através das amostras aleatórias de cada coorte, em cada período de tempo, pode-se construir uma base de dados como se dados em painel estivessem disponíveis (Deaton, 1985, Browning et alii, 1985).

Para definir as coortes são usados o ano de nascimento e o nível de qualificação dos indivíduos. Dessa maneira, em cada ano da pesquisa os indivíduos são divididos em três grupos de qualificação, e em cada um desses, em mais um subgrupo para cada ano de nascimento. Portanto, para cada período são obtidas 105 observações, já que a amostra inclui indivíduos entre 25 e 59 anos. Nos 17 anos de PNAD utilizados, tem-se então 1785 observações.

Um problema com essa metodologia é que os indivíduos em uma coorte são diferentes de um período de tempo para outro. Em cada coorte as médias das variáveis podem ser usadas para aproximar as verdadeiras médias populacionais das coortes, que não são observadas. Entretanto, como ressaltado por Deaton (1985), essas médias baseadas nas amostras apenas podem estimar as verdadeiras coortes populacionais com erros de medida, o que pode levar a estimativas inconsistentes. Nesse caso, todas as variáveis, exceto as dummies, estão sujeitas a erros.

Se o tamanho amostral das coortes é suficientemente grande, os erros amostrais tendem para zero, e as verdadeiras médias das coortes podem ser substituídas pelas médias amostrais. ${ }^{9}$ Embora possa parecer inferior, esse método apresenta algumas vantagens em relação ao uso de dados em painel, pois como a representatividade das coortes é constante, não há problema de atrito. Outra vantagem é que os erros de medida são minimizados quando as médias amostrais são usadas como estimativas das médias populacionais.

A tabela 3 do apêndice apresenta informações sobre o número de observações da PEA em cada coorte. A menor coorte, entre todas as 1785 utilizadas nesse caso, tem 53 observações. Nas coortes mais antigas de trabalhadores qualificados há um número menor de observações. Excetuando esses casos, a grande maioria das coortes apresenta tamanho mínimo superior a 300 observações. Como cada coorte apresenta um número de observações bastante grande, as médias amostrais devem ser boas aproximações das verdadeiras médias populacionais permitindo estimar o modelo com cross-sections repetidas como se tivéssemos dados em painel. Para ter mais garantias de que essa hipótese é satisfeita, as regressões também são estimadas excluindo as coortes de indivíduos com 55 anos ou mais, evitando os números mais baixos de observações nas coortes de trabalhadores qualificados com mais idade. De uma forma geral, os resultados são bastante semelhantes aos encontrados quando são utilizados os trabalhadores entre 25 e 59 anos.

Usando dados de indivíduos pertencentes a PEA, são calculadas, em cada coorte, as taxas de desemprego total e de longo prazo e a razão entre desempregados de longo prazo e o total de trabalhadores desempregados. Também em cada uma das células é calculada a média da aposentadoria domiciliar per capita, ${ }^{10}$ e as evidências empíricas são baseadas nos efeitos dessa variável sobre o desemprego.

\footnotetext{
${ }^{9}$ Esse é o método normalmente empregado na literatura (Baltagi, 1995). Caso as médias amostrais não sejam uma boa aproximação para as verdadeiras médias populacionais, Deaton (1985) propõe um método de correção para os erros de medida utilizando dados individuais para estimar a variância do erro.

${ }^{10}$ Embora a razão entre a aposentadoria per capita e o rendimento médio seja uma representação melhor da importância da aposentadoria para o salário de reserva dos indivíduos, deve haver endogeneidade dessa variável em relação à taxa de desemprego.
} 
Vários controles são incluídos nas regressões. Como as gerações mais novas encontraram taxas de desemprego cada vez mais altas, os efeitos fixos devem captar essa tendência de aumento, com coeficientes maiores para as coortes mais novas. O desemprego também varia entre grupos de idade pelos efeitos da experiência no mercado de trabalho sobre a produtividade, e pelas diferenças na intensidade de busca e no salário de reserva. ${ }^{11} \mathrm{~A}$ idade é representada nas regressões por variáveis dummy ou por polinômios. ${ }^{12}$

As condições macroeconômicas também devem influenciar o desemprego de todos os grupos em cada período de tempo. Aumentos no nível de atividade devem levar a uma redução da taxa de desemprego, e para captar esses efeitos são incluídas as variações do logaritmo do PIB entre dois períodos de tempo. Maiores taxas de inflação podem tornar os salários mais flexíveis, levando a uma redução do desemprego (Card e Hyslop, 1996). Conseqüentemente, a estabilização da inflação após o Plano Real pode ter contribuído para uma maior taxa de desemprego, ao aumentar a rigidez salarial. Esse efeito é captado pela taxa de inflação, que assim como o PIB é igual para todas as coortes em um mesmo período de tempo.

A especificação básica adotada para estimar a relação entre renda de aposentadoria e taxa de desemprego é a seguinte:

$$
u_{c t}=\alpha_{c}+I_{c t}+\beta\left(\Delta P I B_{t}\right)+\eta\left(\text { Inflacao }_{t}\right)+\gamma\left(A_{c t}\right)+\epsilon_{c t}
$$

onde: $u_{c t}$ é taxa de desemprego na coorte $c$ no período $t ; \alpha_{c}$ é efeito fixo da coorte $c$; $I_{c t}$ dummies ou polinômios de idade; $\Delta P I B_{t}$ variação no logaritmo do PIB entre os períodos $t$ e $t-1 ;$ Inflacao $t$ taxa de inflação no período $t$ medida pelo INPC de setembro; $A_{c t}$ aposentadoria. Essa variável é representada pelo logaritmo da média da aposentadoria domiciliar per capita em cada célula.

A equação (1) é estimada separadamente para cada um dos grupos de qualificação. Os efeitos da aposentadoria sobre a taxa de desemprego também são estimados usando dados de todos os grupos de qualificação, mas os coeficientes da idade, da renda da aposentadoria e os efeitos fixos são específicos de cada grupo, através de interações entre essas variáveis e dummies para os grupos de qualificação. Todas as regressões são implementadas pelo método de mínimos quadrados ponderados, em que o número relativo de indivíduos na força de trabalho em cada célula é utilizado como peso.

Maiores aposentadorias podem ter efeito também sobre a taxa de desemprego de longo prazo $\left(u_{c t}^{L P}\right)$, pois aumentando o salário de reserva, os trabalhadores se tornam mais seletivos na escolha do emprego, preferindo um período maior de desemprego para tentar obter um salário mais alto. Para testar a hipótese de que maiores rendas provenientes de aposentadoria levam a aumentos no desemprego de longo prazo é estimada a seguinte equação:

$$
u_{c t}^{L P}=\alpha_{c}+I_{c t}+\beta\left(\Delta P I B_{t}\right)+\eta\left(\text { Inflacao }_{t}\right)+\gamma\left(A_{c t}\right)+\epsilon_{c t}
$$

A aposentaria também pode influenciar a participação dos desempregados de longo prazo no desemprego total. Usando como variável dependente a proporção dos desempregados que estão sem emprego há mais de 1 ano em cada coorte em cada período de tempo $\left(P_{c t}^{L P}\right)$, esse efeito é testado estimando a seguinte equação:

$$
P_{c t}^{L P}=\alpha_{c}+I_{c t}+\beta\left(\Delta P I B_{t}\right)+\eta\left(\text { Inflacao }_{t}\right)+\gamma\left(A_{c t}\right)+\epsilon_{c t}
$$

De acordo com as evidências empíricas para a curva de salário (Blanchflower e Oswald, 1994), maiores taxas de desemprego estão associadas a menores rendimentos. Dessa maneira, maiores taxas de desemprego levam a uma redução dos rendimentos e conseqüentemente a uma maior razão entre aposentadoria e rendimentos.

${ }^{11}$ Para mais evidências no caso brasileiro de diferenças na taxa de desemprego entre grupos de idade, ver Camargo e Reis (2005).

${ }^{12}$ Pelo fato de variáveis para coorte e idade terem sido incluídas, a utilização de dummies de tempo não permitiria identificar o modelo (Deaton e Paxson, 1994). Por isso, os efeitos temporais são captados por variáveis macroeconômicas, como o PIB e a inflação. 
Outros resultados são obtidos a partir das estimativas das probabilidades de desemprego e de desemprego de longo prazo com dados individuais. Dividindo os indivíduos por qualificação, essas probabilidades são estimadas através de um logit com dummies para as coortes de nascimento:

$$
\operatorname{Pr} o b\left(y_{i t}=1\right)=F\left(\alpha_{i}, I_{i t}, \Delta P I B_{t}, \text { Inflacao }_{t}, A_{i t}, X_{i t}, \omega_{i t}\right)
$$

onde a variável $y_{i t}$ assume o valor 1 no caso do trabalhador $i$ se encontrar desempregado e 0 caso contrário. $X_{i t}$ é uma matriz de características individuais e $\omega_{i t}$ é o erro da regressão, que tem distribuição logística.

As mesmas estratégias descritas acima são utilizadas para estimar os efeitos da aposentadoria domiciliar per capita sobre as taxas de participação e de não-emprego. Nesses casos, as variáveis em cada coorte são calculadas usando todos os indivíduos entre 25 e 59 anos.

Algumas considerações devem ser feitas quanto à metodologia utilizada. Não é possível estimar os modelos acima incluindo dummies de tempo. Com isso, mudanças ocorridas ao longo do período que afetassem todos os indívios da mesma forma, não estariam sendo consideradas, exceto os choques agregados representados pelo PIB e a inflação. Como a seção 2 procurou mostrar, os anos noventa foram marcados por alterações bastante intensas na estrutura da demanda por trabalho. As dummies de coorte captariam os impactos de alterações ao longo das gerações, mas isso não é suficiente para tratar de mudanças que tenham influenciado diferentes coortes em um determinado período de tempo. A importância desses efeitos deve ser menor nas regressões separadas por grupo de escolaridade usando dados individuais.

\section{EVIDÊNCIAS EMPÍRICAS PARA OS EFEITOS DA APOSENTADORIA DOMICILIAR PER CAPITA SOBRE O DESEMPREGO}

Os resultados empíricos para os efeitos da aposentadoria sobre o desemprego são apresentados em três subseções. Primeiramente, são apresentados os resultados básicos correspondentes as equações (1), (2) e (3). A segunda subseção contém os resultados para algumas especificações alternativas, que consistem na inclusão da variável dependente defasada e na utilização de toda a amostra com interações entre as dummies de qualificação e a aposentadoria domiciliar per capita. Na subseção seguinte são mostrados os resultados estimados com dados individuais. ${ }^{13}$

\subsection{Resultados Básicos}

A tabela 6 mostra os resultados estimados usando a equação (1) para os trabalhadores não-qualificados. Na coluna (i) são usadas como variáveis de controle efeitos fixos para as coortes, dummies de idade, a taxa de inflação e a variação no logaritmo do PIB em relação ao ano anterior. Na coluna (ii) a taxa de inflação é substituída por uma dummy, que é igual a 1 para o período posterior ao Plano Real, com a inflação estabilizada, e zero no período anterior. A diferença da coluna (iii) em relação a primeira é que a idade é representada por um polinômio de terceiro grau e são usados controles regionais, representados pelas proporções de trabalhadores com a qualificação analisada em cada uma das regiões do país. Na regressão apresentada na coluna (iv) os indivíduos que recebem diretamente aposentadoria são excluídos da amostra.

Em todas as especificações os coeficientes da aposentadoria domiciliar per capita são positivos e significativamente diferentes de zero. De acordo com esses resultados, portanto, aumentos na aposentadoria estão associados a aumentos na taxa de desemprego para os trabalhadores não-qualificados.

\footnotetext{
${ }^{13} \mathrm{E}$ importante ressaltar que os dados da PNAD correspondem a uma amostra estratificada com 3 estágios. A primeira estratificação se refere aos municípios. Em seguida, são selecionados os setores dentro de cada município, e depois os domicílios. Os métodos usados nas estimações supõem uma amostra aleatória simples. Por isso, os erros-padrão aqui apresentados devem ter um viés para baixo. As diferenças, no entanto, normalmente são pequenas (ver, por exemplo, Mare (1980)).
} 
Tabela 8 - Efeitos da Aposentadoria sobre a Taxa de Desemprego (não-qualificados)

\begin{tabular}{|l|c|c|c|c|}
\hline \multicolumn{5}{|c|}{ Variável dependente: Taxa de desemprego } \\
\hline & $(\mathrm{i})$ & $(\mathrm{ii})$ & $(\mathrm{iii})$ & (iv) $^{* * *}$ \\
\hline Aposentadoria & 0,011 & 0,010 & 0,009 & 0,011 \\
domiciliar per capita & $(3.73)$ & $(3.68)$ & $(3.28)$ & $(4.35)$ \\
& & & & \\
Inflação & $-0,0002$ & & $-0,0002$ & $-0,0002$ \\
& $(3.39)$ & & $(3.43)$ & $(3.32)$ \\
Dummy: estabilização da inflação* & & 0,012 & & \\
$\Delta$ PIB & & $(4.36)$ & & \\
& $-0,142$ & $-0,142$ & $-0,140$ & $-0,140$ \\
Intercepto & $(7.13)$ & $(7.69)$ & $(7.53)$ & $(6.97)$ \\
& $-0,059$ & $-0,035$ & $-0,039$ & $-0,057$ \\
\hline Efeitos fixos para as coortes & $(8.7)$ & $(3.65)$ & $(3.29)$ & $(8.13)$ \\
Dummies de idade & Sim & Sim & Sim & Sim \\
Polinômio de terceiro grau para a idade & Sim & Sim & & Sim \\
Controles regionais** & & & Sim & \\
\hline R-quadrado & & & Sim & \\
Número de observações & 0,80 & 0,80 & 0,80 & 0,80 \\
\hline
\end{tabular}

Notas: As regressões são estimadas por mínimos quadrados ponderados. O número relativo de indivíduos em cada célula é usado como ponderador.

As estatísticas-t, obtidas a partir de erros-padrão robustos, são mostradas entre parênteses.

* A dummy para estabilização da inflação é igual a 1 para períodos posteriores a 1994 e zero caso contrário.

** Os controles regionais são as proporções de trabalhadores não-qualificados em cada região.

*** Os indivíduos que recebem diretamente renda de aposentadoria são excluídos.

Tabela 9 - Efeitos da Aposentadoria sobre a Taxa de Desemprego (semi-qualificados)

\begin{tabular}{|l|c|c|c|c|}
\hline \multicolumn{5}{|c|}{ Variável dependente: Taxa de desemprego } \\
\hline & $(\mathrm{i})$ & $(\mathrm{ii})$ & $(\mathrm{iii})$ & (iv) $^{* * *}$ \\
\hline Aposentadoria & 0,004 & 0,004 & 0,004 & 0,002 \\
domiciliar per capita & $(1.37)$ & $(1.39)$ & $(1.21)$ & $(0.78)$ \\
& & & & \\
Inflação & $-0,0002$ & & $-0,0002$ & $-0,0002$ \\
& $(3.1)$ & & $(3.59)$ & $(3.19)$ \\
Dummy: estabilização da inflação* & & 0,010 & & \\
$\Delta$ PIB & & $(3.41)$ & & \\
& $-0,120$ & $-0,123$ & $-0,124$ & $-0,117$ \\
Intercepto & $(5.64)$ & $(6.21)$ & $(6.26)$ & $(5.48)$ \\
& $-0,029$ & $-0,010$ & $-0,075$ & $-0,020$ \\
\hline Efeitos fixos para as coortes & $(3.47)$ & $(0.91)$ & $(5.91)$ & $(2.72)$ \\
dummies de idade & Sim & Sim & Sim & Sim \\
Polinômio de terceiro grau para a idade & Sim & Sim & & Sim \\
Controles regionais** & & & Sim & \\
\hline R-quadrado & & & Sim & \\
Número de observações & 0,85 & 0,85 & 0,86 & 0,86 \\
\hline
\end{tabular}

Notas: As regressões são estimadas por mínimos quadrados ponderados. O número relativo de indivíduos em cada célula é usado como ponderador.

As estatísticas-t, obtidas a partir de erros-padrão robustos, são mostradas entre parênteses.

* A dummy para estabilização da inflação é igual a 1 para períodos posteriores a 1994 e zero caso contrário.

** Os controles regionais são as proporções de trabalhadores semi-qualificados em cada região.

*** Os indivíduos que recebem diretamente renda de aposentadoria são excluídos. 
Quanto aos resultados para outras variáveis, aumentos no PIB e na taxa de inflação têm o efeito de reduzir a taxa de desemprego, como se esperava. A variável dummy para o período de estabilização apresenta coeficientes significativamente positivos.

Na tabela 9 são apresentados os resultados usando a amostra de trabalhadores semi-qualificados. Nas quatro especificações adotadas, a aposentadoria domiciliar per capita apresenta coeficientes positivos, mas em nenhum caso significativo para o nível de $10 \%$. Os resultados para o PIB e a inflação são semelhantes aos da tabela 8 .

A tabela 10 mostra os resultados estimados para os trabalhadores qualificados. As conclusões são bem parecidas com as obtidas no caso dos trabalhadores semi-qualificados. Os efeitos da aposentadoria domiciliar per capita sobre a taxa de desemprego também não são significativos.

Tabela 10 - Efeitos da Aposentadoria sobre a Taxa de Desemprego (qualificados)

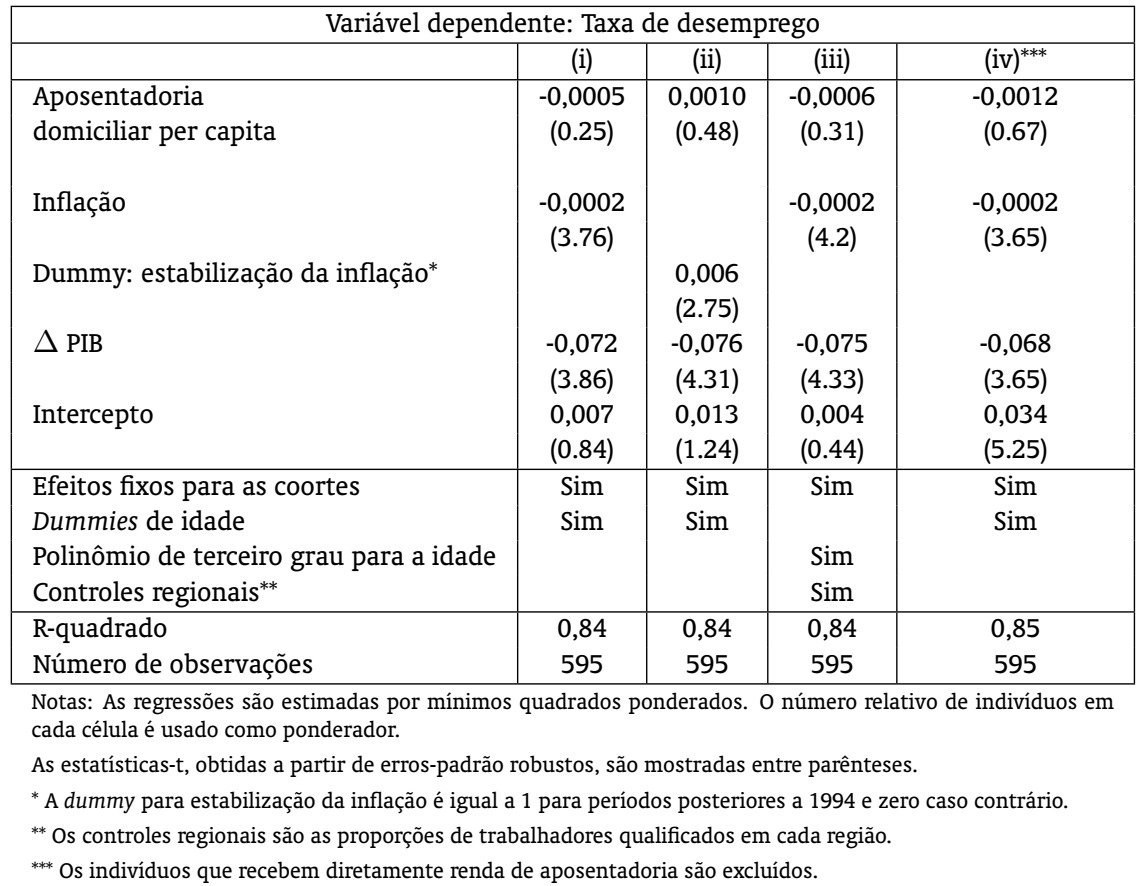

De acordo com os resultados dessas três tabelas 10 , portanto, apenas para os trabalhadores nãoqualificados são encontradas evidências de que maiores aposentadorias levam a aumentos na taxa de desemprego em todas as regressões. Para os demais grupos, não são encontrados resultados significativos.

Os efeitos da aposentadoria sobre a taxa de desemprego de longo prazo, obtidos a partir da equação (2), são representados na tabela 11. De acordo com os resultados, aumentos na aposentadoria domiciliar per capita levam a aumentos nas taxas de desemprego de longo prazo dos trabalhadores não-qualificados e semi-qualificados, nas colunas (i) e (ii). Para os qualificados, porém, o coeficiente dessa variável não é significativamente diferente de zero (coluna (iii)). Aumentos na inflação e no PIB reduzem as taxas de desemprego de longo prazo para todos os grupos de trabalhadores.

A tabela 12 mostra os resultados estimados para a equação (3), em que a variável dependente é a proporção de desempregados de longo prazo no total de trabalhadores desempregados. Pode-se notar, pelas colunas (i) e (ii), que aumentos na aposentadoria domiciliar per capita levam a aumentos na proporção de desempregados de longo prazo para os não-qualificados e os semi-qualificados. 0 resultado para os trabalhadores qualificados não é significativamente diferente de zero. A taxa de inflação 
apresenta resultados não-significativos e o coeficiente do PIB passa a ser positivo e significativamente diferente de zero. Esse resultado para o PIB está de acordo com o argumento de Blanchard e Diamond (1994) de que nos períodos de recuperação da economia as firmas preferem contratar os trabalhadores há menos tempo desempregados, e com isso, ocorre um aumento na proporção de desempregados de longo prazo no total de trabalhadores desempregados.

Portanto, de acordo com os resultados estimados, aumentos na aposentadoria levam a aumentos na taxa de desemprego dos trabalhadores não-qualificados. Esses resultados são válidos para as diferentes especificações adotadas. Para os trabalhadores semi-qualificados e qualificados os efeitos da aposentadoria sobre a taxa de desemprego não se mostraram significativos. Os resultados também indicam que maiores aposentadorias têm como conseqüência o aumento nas taxas de desemprego de longo prazo de não-qualificados e semi-qualificados. As proporções de desempregados de longo prazo nesses dois grupos também parecem aumentar como resultado de aposentadorias mais elevadas. ${ }^{14}$

Tabela 11 - Efeitos da Aposentadoria sobre a Taxa de Desemprego de Longo Prazo

\begin{tabular}{|l|c|c|c|}
\hline \multicolumn{4}{|c|}{$\begin{array}{c}\text { Variável dependente: Taxa de desemprego de longo prazo } \\
\text { (desempregados há mais de 1 ano sem emprego) }\end{array}$} \\
\hline & $\begin{array}{c}\text { Não-qualificados } \\
\text { (i) }\end{array}$ & $\begin{array}{c}\text { Semi-qualificados } \\
\text { (ii) }\end{array}$ & $\begin{array}{c}\text { Qualificados } \\
\text { (iii) }\end{array}$ \\
\hline Aposentadoria & 0,0056 & 0,0062 & 0,0005 \\
domiciliar per capita & $(3.76)$ & $(3.62)$ & $(0.32)$ \\
& & & \\
Inflação & $-0,0001$ & $-0,0001$ & $-0,0001$ \\
& $(3.82)$ & $(2.24)$ & $(3.61)$ \\
$\Delta$ PIB & $-0,042$ & $-0,049$ & $-0,034$ \\
& $(4.50)$ & $(4.36)$ & $(2.60)$ \\
Intercepto & $-0,044$ & $-0,045$ & $-0,013$ \\
& $(9.49)$ & $(8.73)$ & $(2.32)$ \\
\hline Efeitos fixos para as coortes & Sim & Sim & Sim \\
Dummies de idade & Sim & Sim & 0,76 \\
\hline R-quadrado & 0,76 & 0,83 & 595 \\
Número de observações & 595 & 595 & Sim \\
\hline
\end{tabular}

Notas: As regressões são estimadas por mínimos quadrados ponderados. O número relativo de indivíduos em cada célula é usado como ponderador.

As estatísticas-t, obtidas a partir de erros-padrão robustos, são mostradas entre parênteses.

\subsection{Outras Especificações}

Para testar a robustez dos resultados encontrados na subseção anterior, são estimadas algumas regressões com especificações alternativas. Na tabela 13 são apresentados resultados de regressões que incluem um termo auto-regressivo, seguindo a proposta de Verbeek e Vella (2008). A taxa de desemprego defasada é positiva e significativa em todas as regressões estimadas, como a tabela 13 mostra. A aposentadoria domiciliar per capita continua apresentando um efeito significativo sobre a taxa de desemprego dos trabalhadores não-qualificados.

A tabela 14 repete a análise anterior usando como variável dependente a taxa de desemprego de longo prazo. Mais uma vez, o componente auto-regressivo se mostra altamente significativo. A aposentadoria domiciliar per capita apresenta efeitos significativamente positivos sobre as taxas de desemprego de longo prazo de trabalhadores não-qualificados e semi-qualificados. Portanto, os resultados dessa subseção mostram que a inclusão de um termo auto-regressivo para as taxas de desemprego não altera as conclusões obtidas na subseção anterior.

\footnotetext{
${ }^{14}$ Replicando as regressões para uma amostra de trabalhadores entre 25 e 54 anos, os resultados encontrados são basicamente os
} mesmos apresentados acima. 
Tabela 12 - Efeitos da Aposentadoria sobre a Proporção de Desempregados de Longo Prazo

\begin{tabular}{|l|c|c|c|}
\hline \multicolumn{3}{|c|}{ Variável dependente: Proporção dos desempregados há mais de 1 ano sem emprego } \\
\hline & $\begin{array}{c}\text { Não-qualificados } \\
\text { (i) }\end{array}$ & $\begin{array}{c}\text { Semi-qualificados } \\
\text { (ii) }\end{array}$ & $\begin{array}{c}\text { Qualificados } \\
\text { (iii) }\end{array}$ \\
\hline Aposentadoria & 0,048 & 0,057 & 0,011 \\
domiciliar per capita & $(2.29)$ & $(2.67)$ & $(0.29)$ \\
Inflação & & & \\
& $-0,0003$ & $-0,0004$ & 0,0002 \\
$\Delta$ PIB & $(0.79)$ & $(1.14)$ & $(0.32)$ \\
& 0,233 & 0,002 & 0,397 \\
Intercepto & $(1.53)$ & $(0.01)$ & $(1.68)$ \\
& $-0,129$ & $-0,308$ & $-0,014$ \\
\hline Efeitos fixos para as coortes & $(1.79)$ & $(4.03)$ & $(0.09)$ \\
Dummies de idade & Sim & Sim & Sim \\
\hline R-quadrado & Sim & Sim & 0,19 \\
Número de observações & 0,38 & 0,45 & 548 \\
\hline
\end{tabular}

Notas: As regressões são estimadas por mínimos quadrados ponderados. O número relativo de indivíduos em cada célula é usado como ponderador.

As estatísticas-t, obtidas a partir de erros-padrão robustos, são mostradas entre parênteses.

Tabela 13 - Efeitos da Aposentadoria sobre a Taxa de Desemprego (modelo auto-regressivo)

\begin{tabular}{|l|c|c|c|}
\hline & $\begin{array}{c}\text { Não-qualificados } \\
\text { (i) }\end{array}$ & $\begin{array}{c}\text { Semi-qualificados } \\
\text { (ii) }\end{array}$ & $\begin{array}{c}\text { Qualificados } \\
\text { (iii) }\end{array}$ \\
\hline Aposentadoria & 0,0054 & 0,0018 & 0,0016 \\
domiciliar per capita & $(2.47)$ & $(0.97)$ & $(1.04)$ \\
& & & \\
Taxa de desemprego em (t-1) & 0,508 & 0,679 & 0,478 \\
& $(13.07)$ & $(21.39)$ & $(10.76)$ \\
Intercepto & $-0,036$ & $-0,030$ & $-0,024$ \\
& $(5.66)$ & $(4.55)$ & $(2.67)$ \\
\hline Efeitos fixos para as coortes & Sim & Sim & Sim \\
Dummies de idade & Sim & Sim & 0,863 \\
\hline R-quadrado & 0,838 & 0,917 & 544 \\
Número de observações & 544 & 544 & \\
\hline
\end{tabular}

Notas: As regressões são estimadas por mínimos quadrados ponderados. O número relativo de indivíduos em cada célula é usado como ponderador.

As estatísticas-t, obtidas a partir de erros-padrão robustos, são mostradas entre parênteses.

Tabela 14 - Efeitos da Aposentadoria sobre a Taxa de Desemprego de Longo Prazo (modelo autoregressivo)

\begin{tabular}{|l|c|c|c|}
\hline & Não-qualificados & Semi-qualificados & Qualificados \\
\hline Aposentadoria & 0,0034 & 0,0036 & 0,0011 \\
domiciliar per capita & $(2.58)$ & $(2.88)$ & $(1.03)$ \\
& & & 0,578 \\
Taxa de desemprego de longo prazo em (t-1) & 0,364 & $(13.05)$ & 0,425 \\
& $(8.73)$ & $-0,028$ & $(8.80)$ \\
Intercepto & $-0,034$ & $(6.38)$ & $-0,029$ \\
& $(8.76)$ & $\operatorname{Sim}$ & $(4.94)$ \\
\hline Efeitos fixos para as coortes & $\operatorname{Sim}$ & Sim \\
Dummies de idade & $\operatorname{Sim}$ & 0,881 & 0,782 \\
\hline R-quadrado & 0,783 & 544 & 544 \\
Número de observações & 544 & & \\
\hline
\end{tabular}


A tabela 15 mostra os resultados estimados usando informações dos três grupos de qualificação nas regressões. Através da interação entre dummies de qualificação e aposentadoria são feitas comparações entre os grupos com relação aos impactos da aposentadoria domiciliar sobre as variáveis de desemprego. Os efeitos fixos de coorte são específicos de cada grupo de qualificação, assim como as tendências de idade.

Tabela 15 - Efeitos da Aposentadoria sobre o Desemprego com a Amostra Completa

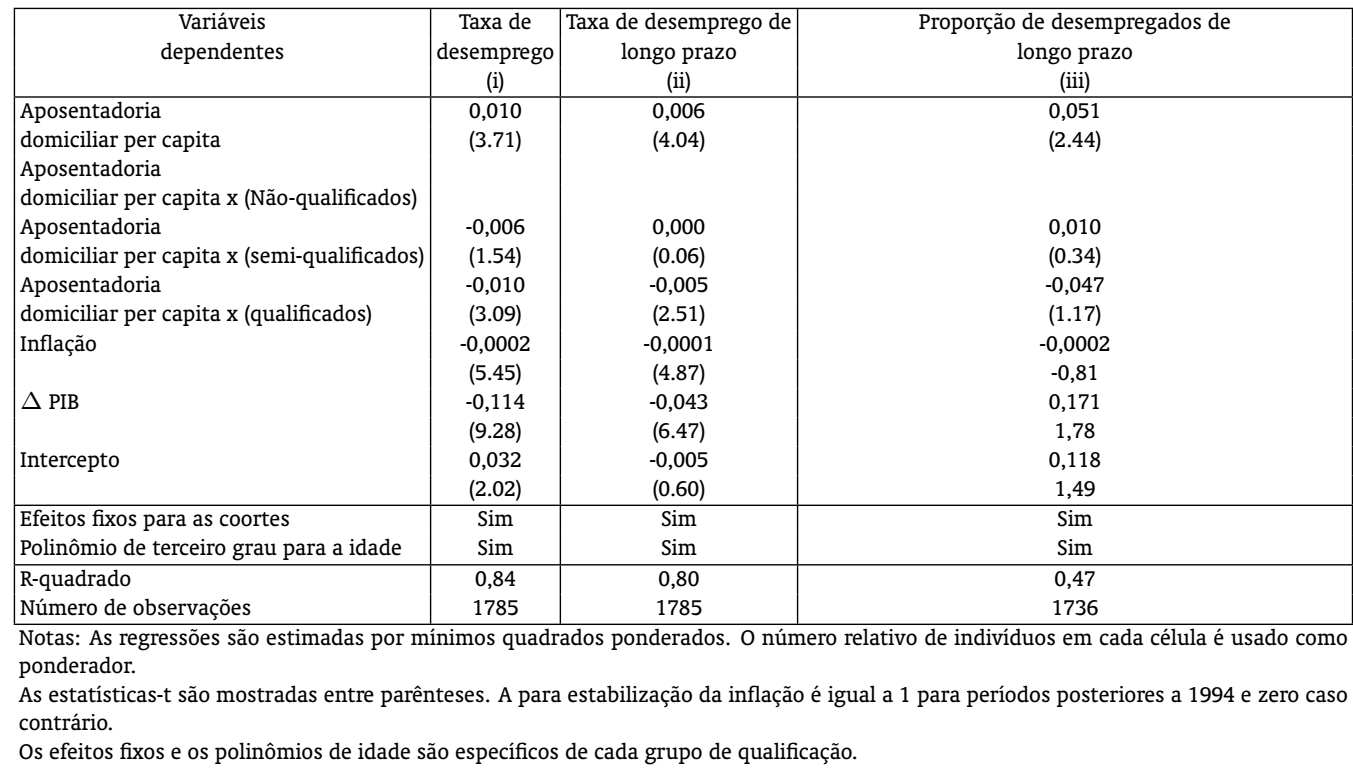

Usando a taxa de desemprego como variável dependente, os resultados na coluna (i) indicam que a aposentadoria domiciliar per capita aumenta o desemprego. As interações entre as dummies de qualificação e a aposentadoria domiciliar per capita mostram que para os trabalhadores qualificados o efeito é significativamente menor do que para os não-qualificados, que é o grupo de referência. As mesmas conclusões são válidas usando a taxa de desemprego de longo prazo, na coluna (ii). O efeito da aposentadoria sobre a proporção de desempregados de longo prazo também é significativamente positivo, e não são encontradas diferenças entre os grupos nesse caso.

\subsection{Resultados com Dados Individuais}

Os resultados das regressões logit para a probabilidade de desemprego, conforme a equação (5.5), são mostrados na tabela 16. Como variáveis de controle são incluídos controles para idade, região, gênero, variações do PIB, inflação e dummies de coorte.

Para os três grupos de qualificação são encontradas evidências de que maiores aposentadorias aumentam a probabilidade de desemprego. A partir dos resultados estimados, são calculados os efeitos marginais de aumentos na aposentadoria sobre a probabilidade de desemprego em cada um dos três grupos de qualificação. Para isso, são definidos grupos de referência formados por homens, de 40 anos, residentes na região Sudeste, nascidos em 1960, em cada grupo de qualificação. A aposentadoria domiciliar per capita, o PIB e a taxa de inflação de referência são as médias em todo o período. Os efeitos marginais são bem mais elevados para os trabalhadores não-qualificados. ${ }^{15}$ De acordo com os resultados, um aumento em R 100 na aposentadoria domiciliar per capita deve aumentar a probabilidade de

${ }^{15}$ Os valores da aposentadoria domiciliar dos trabalhadores qualificados são mais altos e também variaram mais em termos absolutos. Entretanto, a diferença dos efeitos marginais entre os não-qualificados e os qualificados é ainda mais acentuada. 
Tabela 16 - Regressões Logit para a Probabilidade de Desemprego

\begin{tabular}{|c|c|c|c|c|c|c|}
\hline & \multicolumn{2}{|c|}{ Não-qualificados } & \multicolumn{2}{|c|}{ Semi-qualificados } & \multicolumn{2}{|c|}{ Qualificados } \\
\hline & $\begin{array}{c}\text { (i) } \\
\text { Coeficiente }\end{array}$ & \begin{tabular}{|c|} 
(ii) \\
Efeitos \\
Marginais
\end{tabular} & \begin{tabular}{c|} 
(iii) \\
Coeficiente
\end{tabular} & \begin{tabular}{|c|} 
(iv) \\
Efeitos \\
Marginais
\end{tabular} & \begin{tabular}{|c|}
$\mathrm{v})$ \\
Coeficiente
\end{tabular} & $\begin{array}{c}\text { (vi) } \\
\text { Efeitos } \\
\text { Marginais }\end{array}$ \\
\hline Aposentadoria domiciliar per capita & $\begin{array}{c}0,0014 \\
(6.11)\end{array}$ & 0,012 & $\begin{array}{c}0,0011 \\
(8.80)\end{array}$ & 0,006 & $\begin{array}{l}0,0005 \\
(15.03)\end{array}$ & 0,002 \\
\hline Idade & $\begin{array}{l}-0,147 \\
(2.21)\end{array}$ & $-1,192$ & $\begin{array}{c}-0,2514 \\
(4.82)\end{array}$ & $-1,488$ & $\begin{array}{l}-0,306 \\
(3.78)\end{array}$ & $-1,150$ \\
\hline Idade ao quadrado & $\begin{array}{l}0,005 \\
(2.70)\end{array}$ & 0,036 & $\begin{array}{c}0,0060 \\
(4.40)\end{array}$ & 0,035 & $\begin{array}{l}0,006 \\
(2.94)\end{array}$ & 0,024 \\
\hline Idade ao cubo & $\begin{array}{l}0,000 \\
(2.44)\end{array}$ & 0,000 & $\begin{array}{c}0,0000 \\
(3.39)\end{array}$ & 0,000 & $\begin{array}{l}0,000 \\
(1.66)\end{array}$ & 0,000 \\
\hline Gênero & $\begin{array}{c}0,242 \\
(12.68)\end{array}$ & 1,955 & $\begin{array}{l}0,3663 \\
(26.96)\end{array}$ & 2,168 & $\begin{array}{c}0,406 \\
(20.19)\end{array}$ & 1,528 \\
\hline Nordeste & $\begin{array}{l}0,137 \\
(3.80)\end{array}$ & 1,109 & $\begin{array}{c}0,2606 \\
(9.54)\end{array}$ & 1,542 & $\begin{array}{l}0,091 \\
(2.47)\end{array}$ & 0,343 \\
\hline Sudeste & $\begin{array}{l}0,250 \\
(6.93)\end{array}$ & 2,027 & $\begin{array}{c}0,1129 \\
(4.35)\end{array}$ & 0,668 & $\begin{array}{l}-0,048 \\
(1.34)\end{array}$ & $-0,179$ \\
\hline Sul & $\begin{array}{l}0,236 \\
(5.80)\end{array}$ & 1,907 & $\begin{array}{c}-0,1599 \\
(5.51)\end{array}$ & $-0,946$ & $\begin{array}{l}-0,385 \\
(9.22)\end{array}$ & $-1,449$ \\
\hline Centro-Oeste & $\begin{array}{l}0,129 \\
(3.10)\end{array}$ & 1,048 & $\begin{array}{c}-0,0840 \\
(2.69)\end{array}$ & $-0,497$ & $\begin{array}{l}-0,356 \\
(8.08)\end{array}$ & $-1,340$ \\
\hline PIB & $\begin{array}{l}-3,551 \\
(12.43)\end{array}$ & $-28,743$ & $\begin{array}{c}-2,8343 \\
(12.8)\end{array}$ & $-16,777$ & $\begin{array}{l}-2,413 \\
(7.00)\end{array}$ & $-9,073$ \\
\hline Inflação & $\begin{array}{l}-0,003 \\
(3.71)\end{array}$ & $-0,026$ & $\begin{array}{c}-0,0032 \\
(5.07)\end{array}$ & $-0,019$ & $\begin{array}{l}-0,004 \\
(4.12)\end{array}$ & $-0,015$ \\
\hline Intercepto & $\begin{array}{l}-4,678 \\
(4.65)\end{array}$ & $-37,871$ & $\begin{array}{c}-1,9993 \\
(2.40)\end{array}$ & $-11,835$ & $\begin{array}{l}-1,118 \\
(0.86)\end{array}$ & $-4,203$ \\
\hline \begin{tabular}{|l|} 
Dummies de coorte \\
\end{tabular} & Sir & & Sir & & & \\
\hline \begin{tabular}{|l} 
Observações \\
Pseudo-R2
\end{tabular} & $\begin{array}{l}3628 \\
0,04\end{array}$ & & $\begin{array}{r}6006 \\
0,0\end{array}$ & & & \\
\hline
\end{tabular}

Fonte: PNAD.

As estatísticas-t são mostradas entre parênteses.

Os efeitos marginais são calculados para o grupo de referência formado por: homens, de 40 anos, na região sudeste, nascidos em 1960. Para o PIB e a inflação são utilizadas as médias para todo o período. A aposentadoria domiciliar per capita é a média de todo o período para cada grupo de qualificação.

desemprego dos trabalhadores não-qualificados em 1,2 ponto percentual. Para os semi-qualificados o aumento é de 0,7 e para os qualificados o aumento estimado é de apenas 0,2 ponto percentual.

No apêndice são apresentados resultados de regressões que incluem algumas características do domicílio e do indivíduo que recebe a aposentadoria. Para os três grupos de qualificação, a probabilidade de desemprego diminui quando a proporção de crianças no domicílio é maior, já que isso deve reduzir o salário de reserva dos trabalhadores. A probabilidade de desemprego de um trabalhador também diminui se a escolaridade média dos outros adultos no domicílio é alta. Esse resultado parece associado ao fato de que pessoas mais escolarizadas devem possuir mais informações, facilitando a colocação do membro do domicílio no mercado de trabalho. O efeito da aposentadoria domiciliar per capita sobre a probabilidade de desemprego é mais alto para os filhos dos aposentados, sugerindo que esses são favorecidos na distribuição da aposentadoria domiciliar entre os membros do domicílio. Em todas essas especificações são mantidos os resultados da tabela 16 , de que aumentos na aposentadoria domiciliar per capita aumentam a probabilidade de desemprego, principalmente para os trabalhadores não-qualificados.

A tabela 17 mostra os resultados estimados para a probabilidade de desemprego de longo prazo. Maiores aposentadorias aumentam essas probabilidades nos três grupos de qualificação, e os efeitos

Entre 81 e 99 a variação na média da aposentadoria domiciliar per capita foi 4 vezes maior para os qualificados do que para os não-qualificados, enquanto os efeitos marginais são cerca de 6 vezes maiores para os não-qualificados em comparação com os qualificados. 
Tabela 17 - Regressões Logit para a Probabilidade de Desemprego de Longo Prazo

\begin{tabular}{|c|c|c|c|c|c|c|}
\hline & \multicolumn{2}{|c|}{ Não-qualificados } & \multicolumn{2}{|c|}{ Semi-qualificados } & \multicolumn{2}{|c|}{ Qualificados } \\
\hline & \begin{tabular}{|c|} 
(i) \\
Coeficiente
\end{tabular} & \begin{tabular}{|c|} 
(ii) \\
Efeitos \\
Marginais
\end{tabular} & $\begin{array}{c}\text { (iii) } \\
\text { Coeficiente }\end{array}$ & \begin{tabular}{|c} 
(iv) \\
Efeitos \\
Marginais
\end{tabular} & $\begin{array}{c}\text { (v) } \\
\text { Coeficiente }\end{array}$ & $\begin{array}{c}\text { (vi) } \\
\text { Efeitos } \\
\text { Marginais }\end{array}$ \\
\hline Aposentadoria domiciliar per capita & $\begin{array}{c}0,0022 \\
(6.97)\end{array}$ & 0,018 & $\begin{array}{c}0,0015 \\
(8.37)\end{array}$ & 0,009 & $\begin{array}{l}0,0006 \\
(14.96)\end{array}$ & 0,002 \\
\hline Idade & $\begin{array}{c}-0,0996 \\
(0.86)\end{array}$ & $-0,807$ & $\begin{array}{c}-0,1397 \\
(1.73)\end{array}$ & $-0,827$ & $\begin{array}{c}-0,1705 \\
(1.55)\end{array}$ & $-0,641$ \\
\hline Idade ao quadrado & $\begin{array}{c}0,0040 \\
(1.40)\end{array}$ & 0,033 & $\begin{array}{c}0,0030 \\
(1.41)\end{array}$ & 0,017 & $\begin{array}{c}0,0025 \\
(0.85)\end{array}$ & 0,009 \\
\hline Idade ao cubo & $\begin{array}{c}0,0000 \\
(1.13)\end{array}$ & 0,000 & $\begin{array}{c}0,0000 \\
(0.29)\end{array}$ & 0,000 & $\begin{array}{c}0,0000 \\
(0.35)\end{array}$ & 0,000 \\
\hline Gênero & $\begin{array}{l}1,0386 \\
(32.43)\end{array}$ & 8,408 & $\begin{array}{l}1,1088 \\
(51.63)\end{array}$ & 6,564 & $\begin{array}{c}0,8457 \\
(29.2)\end{array}$ & 3,180 \\
\hline Nordeste & $\begin{array}{c}0,0688 \\
(1.22)\end{array}$ & 0,557 & $\begin{array}{c}0,2392 \\
(6.11)\end{array}$ & 1,416 & $\begin{array}{c}0,0718 \\
(1.49)\end{array}$ & 0,270 \\
\hline Sudeste & $\begin{array}{c}0,0927 \\
(1.61)\end{array}$ & 0,750 & $\begin{array}{c}-0,0823 \\
(2.17)\end{array}$ & $-0,487$ & $\begin{array}{c}-0,1901 \\
(4.04)\end{array}$ & $-0,715$ \\
\hline Sul & $\begin{array}{c}-0,1078 \\
(1.61)\end{array}$ & $-0,873$ & $\begin{array}{r}-0,5241 \\
(11.88)\end{array}$ & $-3,103$ & $\begin{array}{l}-0,6202 \\
(10.83)\end{array}$ & $-2,332$ \\
\hline Centro-Oeste & $\begin{array}{c}-0,1366 \\
(1.98)\end{array}$ & $-1,106$ & $\begin{array}{c}-0,3377 \\
(7.18)\end{array}$ & $-1,999$ & $\begin{array}{c}-0,4887 \\
(8.27)\end{array}$ & $-1,838$ \\
\hline PIB & $\begin{array}{c}-2,5159 \\
(4.68)\end{array}$ & $-20,367$ & $\begin{array}{c}-2,6916 \\
(7.31)\end{array}$ & $-15,932$ & $\begin{array}{c}-2,0175 \\
(4.24)\end{array}$ & $-7,587$ \\
\hline Inflação & $\begin{array}{c}-0,0015 \\
(1.01)\end{array}$ & $-0,012$ & $\begin{array}{c}-0,0019 \\
(1.95)\end{array}$ & $-0,012$ & $\begin{array}{c}-0,0039 \\
(2.95)\end{array}$ & $-0,015$ \\
\hline Intercepto & $\begin{array}{c}-8,4662 \\
(4.90)\end{array}$ & $-68,536$ & $\begin{array}{c}-6,1909 \\
(4.57)\end{array}$ & $-36,646$ & $\begin{array}{c}-4,6988 \\
(2.62)\end{array}$ & $-17,670$ \\
\hline Dummies de coorte & Sin & & Sin & & & \\
\hline $\begin{array}{l}\text { Observações } \\
\text { Pseudo-R2 }\end{array}$ & $\begin{array}{l}3628 \\
0,04\end{array}$ & & $\begin{array}{r}6006 \\
0,0\end{array}$ & & & $\begin{array}{l}58 \\
67\end{array}$ \\
\hline
\end{tabular}

marginais também mostram que o impacto é mais acentuado para os não-qualificados. Para os mesmos grupos de referência definidos acima, um aumento em $\mathrm{R} \$ 100$ na aposentadoria domiciliar per capita aumenta a probabilidade de desemprego de longo prazo para os trabalhadores não-qualificados, semiqualificados e qualificados em torno de 0,6; 0,35 e 0,1 ponto percentual, respectivamente.

\section{EVIDÊNCIAS EMPÍRICAS PARA AS TAXAS DE PARTICIPAÇÃO E DE NÃO-EMPREGO}

Nesta seção são apresentados os resultados estimados para o efeito da aposentadoria domiciliar per capita sobre a taxa de participação no mercado de trabalho e a taxa de não-emprego. A abordagem é a mesma utilizada para avaliar os efeitos sobre o desemprego, embora possam ser citados vários fatores que influenciam especificamente a decisão de participação, como doença ou incapacidade e as necessidades de cuidar de dependentes ou de realizar trabalhos domésticos sem remuneração. ${ }^{16}$ Na subseção 7.1 são mostradas as estimativas usando as médias por coorte, e na subseção 7.2 são apresentados os resultados com dados individuais.

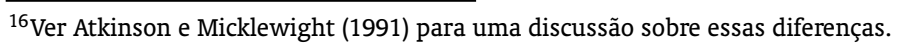




\subsection{Resultados com Dados de Coortes}

A tabela 18 apresenta os resultados para a taxa de participação. Pode-se notar que os efeitos da aposentadoria domiciliar per capita sobre a taxa de participação são negativos e significativos para os não-qualificados e os semi-qualificados, ou seja, aumentos na aposentadoria domiciliar per capita reduzem a taxa de participação. Para os qualificados os coeficientes não são significativamente diferentes de zero. Os resultados também mostram que para os não-qualificados maiores taxas de inflação levam a aumentos na participação, mas as variações no PIB não são significativas. Já para os semi-qualificados e os qualificados os coeficiente da taxa de inflação são não-significativos, enquanto as variações no PIB passam a apresentar efeitos positivos sobre a taxa de participação.

Os resultados para a taxa de não-emprego, apresentados na tabela 19, mostram que maiores aposentadorias aumentam o não-emprego para os não-qualificados e os semi-qualificados, enquanto os efeitos sobre os qualificados não são significativos.

Tabela 18 - Regressões Logit para a Probabilidade de Desemprego de Longo Prazo

\begin{tabular}{|c|c|c|c|}
\hline Variável dependente: Taxa de desemprego & Não-qualificados & Semi-qualificados & Qualificados \\
\hline & (i) & (ii) & (iii) \\
\hline $\begin{array}{l}\text { Aposentadoria } \\
\text { domiciliar per capita }\end{array}$ & $\begin{array}{l}-0,016 \\
(3.10)\end{array}$ & $\begin{array}{r}-0,012 \\
(2.94)\end{array}$ & $\begin{array}{c}0,0005 \\
(0.15)\end{array}$ \\
\hline Proporção de indivíduos recebendo aposentadoria & $\begin{array}{c}-0,314 \\
(4.18)\end{array}$ & $\begin{array}{l}-0,32 \\
(4.14)\end{array}$ & $\begin{array}{l}-0,319 \\
(5.14)\end{array}$ \\
\hline Inflação & $\begin{array}{c}0,0002 \\
(2.51)\end{array}$ & $\begin{array}{c}-0,00002 \\
(0.29)\end{array}$ & $\begin{array}{c}-0,00002 \\
(0.27)\end{array}$ \\
\hline$\Delta \mathrm{PIB}$ & $\begin{array}{l}0,021 \\
(1.00)\end{array}$ & $\begin{array}{l}0,046 \\
(2.75)\end{array}$ & $\begin{array}{l}0,088 \\
(4.34)\end{array}$ \\
\hline Intercepto & $\begin{array}{c}0,525 \\
(50.76)\end{array}$ & $\begin{array}{c}0,588 \\
(49.35)\end{array}$ & $\begin{array}{c}0,905 \\
(36.41)\end{array}$ \\
\hline Efeitos fixos para as coortes & $\operatorname{Sim}$ & Sim & Sim \\
\hline R-quadrado & 0,95 & 0,968 & 0,954 \\
\hline Número de observações & 595 & 595 & 595 \\
\hline
\end{tabular}

\subsection{Resultados com Dados Individuais}

A tabela 20 apresenta as regressões logit para a probabilidade de participação, incluindo como variáveis de controle idade, região, gênero, variações do PIB, inflação e dummies de coorte. De acordo com os resultados, a aposentadoria domiciliar per capita reduz a probabilidade de participação nos três grupos de qualificação.

Os efeitos marginais das variáveis são calculados usando o mesmo grupo de referência adotado nas tabelas 16 e 17 para a taxa de desemprego. Os resultados mostram que um aumento de RS 100 na aposentadoria domiciliar per capita reduz a probabilidade de participação dos trabalhadores não-qualificados em 8,6 pontos percentuais. As reduções estimadas para os semi-qualificados e os qualificados são de 2,3 e 0,4 ponto percentual, respectivamente.

As regressões logit para a probabilidade de não-emprego são mostradas na tabela 21 . Nos três grupos de qualificação, os resultados estimados mostram que maiores aposentadorias aumentam a probabilidade do indivíduo se encontrar sem emprego, desempregado ou não participando do mercado de trabalho. De acordo com os resultados estimados, um aumento na aposentadoria domiciliar per capita de R\$ 100 aumenta as probabilidades de não-emprego para não-qualificados, semi-qualificados e qualificados em 13,2; 4,1 e 0,7 ponto percentual, respectivamente. 
Tabela 19 - Efeitos da Aposentadoria sobre a Taxa de Não-emprego

\begin{tabular}{|c|c|c|c|}
\hline $\begin{array}{l}\text { Variável dependente: } \\
\text { Taxa de desemprego }\end{array}$ & Não-qualificados & Semi-qualificados & Qualificados \\
\hline & (i) & (ii) & (iii) \\
\hline Aposentadoria & 0,024 & 0,015 & $-0,003$ \\
\hline domiciliar per capita & (3.97) & (3.19) & $(0.70)$ \\
\hline \multirow[t]{2}{*}{ Proporção de indivíduos recebendo aposentadoria } & 0,240 & 0,330 & 0,339 \\
\hline & (2.79) & (3.79) & $(5.52)$ \\
\hline \multirow{2}{*}{ Inflação } & $-0,0003$ & $-0,0001$ & $-0,0001$ \\
\hline & $(3.66)$ & $(1.52)$ & $(2.14)$ \\
\hline \multirow{2}{*}{$\Delta \mathrm{PIB}$} & $-0,108$ & $-0,128$ & $-0,143$ \\
\hline & $(4.39)$ & $(6.18)$ & $(6.46)$ \\
\hline \multirow{2}{*}{ Intercepto } & 0,427 & 0,386 & 0,112 \\
\hline & $(40.44)$ & (27.93) & $(4.36)$ \\
\hline Efeitos fixos para as coortes & Sim & Sim & Sim \\
\hline Dummies de idade & Sim & $\operatorname{Sim}$ & Sim \\
\hline R-quadrado & 0,93 & 0,95 & 0,94 \\
\hline Número de observações & 595 & 595 & 595 \\
\hline
\end{tabular}

Notas: As regressões são estimadas por mínimos quadrados ponderados. O número relativo de indivíduos em cada célula é usado como ponderador.

As estatísticas-t, obtidas a partir de erros-padrão robustos, são mostradas entre parênteses.

Tabela 20 - Regressões Logit para a Probabilidade de Participar da PEA

\begin{tabular}{|c|c|c|c|c|c|c|}
\hline & \multicolumn{2}{|c|}{ Não-qualificados } & \multicolumn{2}{|c|}{ Semi-qualificados } & \multicolumn{2}{|c|}{ Qualificados } \\
\hline & $\begin{array}{c}\text { (i) } \\
\text { Coeficiente }\end{array}$ & $\begin{array}{c}\text { (ii) } \\
\text { Efeitos } \\
\text { Marginais }\end{array}$ & $\begin{array}{c}\text { (iii) } \\
\text { Coeficiente }\end{array}$ & \begin{tabular}{|c|} 
(iv) \\
Efeitos \\
Marginais
\end{tabular} & $\begin{array}{c}\text { (v) } \\
\text { Coeficiente }\end{array}$ & $\begin{array}{c}\text { (vi) } \\
\text { Efeitos } \\
\text { Marginais }\end{array}$ \\
\hline Aposentadoria domiciliar per capita & $\begin{array}{l}-0,014 \\
(55.99)\end{array}$ & $-0,09$ & $\begin{array}{l}-0,006 \\
(55.46)\end{array}$ & $-0,02$ & $\begin{array}{l}-0,001 \\
(36.68)\end{array}$ & 0,00 \\
\hline Idade & $\begin{array}{l}0,180 \\
(6.68)\end{array}$ & 1,08 & $\begin{array}{l}-0,059 \\
(2.48)\end{array}$ & $-0,24$ & $\begin{array}{l}-0,016 \\
(0.45)\end{array}$ & $-0,05$ \\
\hline Idade ao quadrado & $\begin{array}{l}-0,002 \\
(3.03)\end{array}$ & $-0,01$ & $\begin{array}{l}0,004 \\
(7.13)\end{array}$ & 0,02 & $\begin{array}{l}0,004 \\
(4.27)\end{array}$ & 0,01 \\
\hline Idade ao cubo & $\begin{array}{l}0,000 \\
(0.27)\end{array}$ & 0,00 & $\begin{array}{c}0,000 \\
(11.13)\end{array}$ & 0,00 & $\begin{array}{l}0,000 \\
(8.42)\end{array}$ & 0,00 \\
\hline Gênero & $\begin{array}{l}-2,632 \\
(299.7)\end{array}$ & $-15,80$ & $\begin{array}{c}-2,810 \\
(344.49)\end{array}$ & $-11,50$ & $\begin{array}{c}-2,169 \\
(165.31)\end{array}$ & $-6,88$ \\
\hline Nordeste & $\begin{array}{r}-0,012 \\
(0.85)\end{array}$ & $-0,07$ & $\begin{array}{l}-0,113 \\
(8.47)\end{array}$ & $-0,46$ & $\begin{array}{l}-0,030 \\
(1.44)\end{array}$ & $-0,10$ \\
\hline Sudeste & $\begin{array}{l}-0,051 \\
(3.71)\end{array}$ & $-0,31$ & $\begin{array}{c}-0,132 \\
(10.79)\end{array}$ & $-0,54$ & $\begin{array}{l}-0,227 \\
(11.59)\end{array}$ & $-0,72$ \\
\hline Sul & $\begin{array}{l}0,013 \\
(0.84)\end{array}$ & 0,08 & $\begin{array}{l}0,048 \\
(3.51)\end{array}$ & 0,19 & $\begin{array}{l}-0,098 \\
(4.46)\end{array}$ & $-0,31$ \\
\hline Centro-Oeste & $\begin{array}{c}-0,074 \\
(4.70)\end{array}$ & $-0,44$ & $\begin{array}{l}-0,034 \\
(2.33)\end{array}$ & $-0,14$ & $\begin{array}{l}-0,064 \\
(2.80)\end{array}$ & $-0,20$ \\
\hline PIB & $\begin{array}{l}0,192 \\
(1.86)\end{array}$ & 1,15 & $\begin{array}{l}0,264 \\
(2.80)\end{array}$ & 1,08 & $\begin{array}{l}0,724 \\
(4.67)\end{array}$ & 2,30 \\
\hline Inflação & $\begin{array}{l}0,001 \\
(2.51)\end{array}$ & 0,01 & $\begin{array}{l}0,000 \\
(0.59)\end{array}$ & 0,00 & $\begin{array}{l}0,000 \\
(0.13)\end{array}$ & 0,00 \\
\hline Intercepto & $\begin{array}{l}-1,969 \\
(5.25)\end{array}$ & $-11,82$ & $\begin{array}{l}1,399 \\
(4.14)\end{array}$ & 5,73 & $\begin{array}{l}2,599 \\
(4.90)\end{array}$ & 8,24 \\
\hline Dummies de coorte & $\mathrm{Sin}$ & & $\mathrm{Sir}$ & & & \\
\hline $\begin{array}{l}\text { Observações } \\
\text { Pseudo-R2 }\end{array}$ & $\begin{array}{r}587 \\
0,2\end{array}$ & $\begin{array}{l}317 \\
25\end{array}$ & $\begin{array}{r}865 \\
0,2\end{array}$ & 430 & & \\
\hline
\end{tabular}

Fonte: PNAD.

As estatísticas-t são mostradas entre parênteses.

Os efeitos marginais são calculados para o grupo de referência formado por: homens, de 40 anos, na região sudeste, nascidos em 1960. Para o PIB e a inflação são utilizadas as médias para todo o período. A aposentadoria domiciliar per capita é a média de todo o período para cada grupo de qualificação. 
Tabela 21 - Regressões Logit para a Probabilidade de Não-emprego

\begin{tabular}{|c|c|c|c|c|c|c|}
\hline & \multicolumn{2}{|c|}{ Não-qualificados } & \multicolumn{2}{|c|}{ Semi-qualificados } & \multicolumn{2}{|c|}{ Qualificados } \\
\hline & $\begin{array}{c}\text { (i) } \\
\text { Coeficiente }\end{array}$ & $\begin{array}{c}\text { (ii) } \\
\text { Efeitos } \\
\text { Marginais }\end{array}$ & $\begin{array}{c}\text { (iii) } \\
\text { Coeficiente }\end{array}$ & \begin{tabular}{|c|} 
(iv) \\
Efeitos \\
Marginais
\end{tabular} & $\begin{array}{c}\text { (v) } \\
\text { Coeficiente }\end{array}$ & $\begin{array}{c}\text { (vi) } \\
\text { Efeitos } \\
\text { Marginais }\end{array}$ \\
\hline Aposentadoria domiciliar per capita & $\begin{array}{l}0,0134 \\
(55.69)\end{array}$ & 0,132 & $\begin{array}{l}0,0052 \\
(56.14)\end{array}$ & 0,041 & $\begin{array}{l}0,0012 \\
(37.55)\end{array}$ & 0,007 \\
\hline Idade & $\begin{array}{c}-0,15 \\
(5.57)\end{array}$ & $-1,43$ & $\begin{array}{c}0,01 \\
(0.62)\end{array}$ & 0,11 & $\begin{array}{c}-0,03 \\
(0.94)\end{array}$ & $-0,18$ \\
\hline Idade ao quadrado & $\begin{array}{c}0,00 \\
(2.66)\end{array}$ & 0,02 & $\begin{array}{c}0,00 \\
(4.72)\end{array}$ & $-0,02$ & $\begin{array}{c}0,00 \\
(2.67)\end{array}$ & $-0,01$ \\
\hline Idade ao cubo & $\begin{array}{c}0,00 \\
(0.24)\end{array}$ & 0,00 & $\begin{array}{c}0,00 \\
(8.53)\end{array}$ & 0,00 & $\begin{array}{c}0,00 \\
(6.82)\end{array}$ & 0,00 \\
\hline Gênero & $\begin{array}{c}2,34 \\
(293.72)\end{array}$ & 23,16 & $\begin{array}{c}2,35 \\
(338.1)\end{array}$ & 18,20 & $\begin{array}{c}1,77 \\
(159.52)\end{array}$ & 10,23 \\
\hline Nordeste & $\begin{array}{c}0,03 \\
(2.51)\end{array}$ & 0,33 & $\begin{array}{c}0,16 \\
(12.36)\end{array}$ & 1,21 & $\begin{array}{c}0,04 \\
(2.10)\end{array}$ & 0,23 \\
\hline Sudeste & $\begin{array}{c}0,09 \\
(6.56)\end{array}$ & 0,85 & $\begin{array}{c}0,14 \\
(11.81)\end{array}$ & 1,06 & $\begin{array}{c}0,16 \\
(9.22)\end{array}$ & 0,95 \\
\hline Sul & $\begin{array}{c}0,03 \\
(1.70)\end{array}$ & 0,26 & $\begin{array}{l}-0,07 \\
(5.31)\end{array}$ & $-0,53$ & $\begin{array}{l}-0,01 \\
(0.47)\end{array}$ & $-0,05$ \\
\hline Centro-Oeste & $\begin{array}{c}0,09 \\
(5.97)\end{array}$ & 0,89 & $\begin{array}{c}0,01 \\
(0.89)\end{array}$ & 0,09 & $\begin{array}{l}-0,03 \\
(1.61)\end{array}$ & $-0,19$ \\
\hline PIB & $\begin{array}{l}-0,65 \\
(6.56)\end{array}$ & $-6,46$ & $\begin{array}{l}-0,72 \\
(8.13)\end{array}$ & $-5,61$ & $\begin{array}{l}-1,05 \\
(7.32)\end{array}$ & $-6,10$ \\
\hline Inflação & $\begin{array}{c}0,00 \\
(5.30)\end{array}$ & $-0,02$ & $\begin{array}{c}0,00 \\
(2.81)\end{array}$ & $-0,01$ & $\begin{array}{c}0,00 \\
(2.66)\end{array}$ & $-0,01$ \\
\hline Intercepto & $\begin{array}{c}1,16 \\
(3.19)\end{array}$ & 11,41 & $\begin{array}{l}-0,93 \\
(2.96)\end{array}$ & $-7,22$ & $\begin{array}{l}-1,85 \\
(3.76)\end{array}$ & $-10,71$ \\
\hline Dummies de coorte & Sir & & Sir & & & \\
\hline $\begin{array}{l}\text { Observações } \\
\text { Pseudo-R2 }\end{array}$ & $\begin{array}{r}587 \\
0,2\end{array}$ & & $\begin{array}{r}865 \\
0,2\end{array}$ & & & \\
\hline
\end{tabular}

Fonte: PNAD.

Os efeitos marginais são calculados para o grupo de referência formado por: homens, de 40 anos, na região sudeste, nascidos em 1960. Para o PIB e a inflação são utilizadas as médias para todo o período. A aposentadoria domiciliar per capita é a média de todo o período para cada grupo de qualificação.

\section{CONCLUSÕES}

O comportamento dos trabalhadores no mercado de trabalho pode ser alterado pelo efeito da aposentadoria sobre a renda domiciliar per capita, mesmo que a aposentadoria seja recebida por outros membros da família no domicílio, que não participam da força de trabalho. Aumentos no valor da aposentadoria domiciliar podem influenciar o salário de reserva dos trabalhadores, fazendo com que esses se tornem mais seletivos com relação às propostas de emprego. Como conseqüência dessa mudança, a pressão salarial seria aumentada, levando a maiores taxas de desemprego, assim como a um desemprego de longo prazo maior. Além disso, aumentos no salário de reserva também poderiam levar alguns trabalhadores a decidir não participar do mercado de trabalho.

Durante a década de noventa a importância da aposentadoria na renda domiciliar aumentou substancialmente, principalmente nos domicílios com trabalhadores não-qualificados. Ao mesmo tempo, ocorreram aumentos na taxa de desemprego, na taxa de desemprego de longo prazo e na proporção de desempregados de longo prazo. Para essas duas primeiras variáveis, os maiores aumentos foram registrados para os trabalhadores não-qualificados.

De acordo com o argumento proposto nesse artigo, as maiores aposentadorias podem ter desempenhado um papel tanto no aumento do desemprego nos anos noventa, quanto nas diferentes trajetórias entre os grupos de qualificação. Para avaliar os efeitos da aposentadoria domiciliar sobre as variáveis de desemprego foram estimadas regressões com cross-sections repetidas de coortes de nascimento e qualificação. Foram estimados também os impactos da aposentadoria sobre as probabilidades de desemprego e de desemprego de longo prazo. A análise empírica foi baseada nos dados da PNAD para o período de 
1981 a 1999.

De acordo com os resultados estimados, maiores aposentadorias têm efeitos positivos e significativos sobre o desemprego dos trabalhadores não-qualificados. Aumentos na aposentadoria domiciliar per capita nos anos noventa parecem ter levado a aumentos na taxa de desemprego, na taxa de desemprego de longo prazo e na proporção de desempregados de longo prazo para esses trabalhadores. No caso dos semi-qualificados foram encontradas algumas evidências de que as aposentadorias influenciaram a taxa de desemprego de longo prazo desse grupo. Para os qualificados não foram encontrados resultados significativos. De acordo com as regressões com dados individuais, maiores aposentadorias domiciliares per capita aumentam as probabilidades de desemprego e de desemprego de longo prazo, principalmente para os não-qualificados. Os resultados também mostram que aumentos na aposentadoria domiciliar per capita reduziram a taxa de participação e aumentaram a taxa de não-emprego para os não-qualificados e os semi-qualificados.

As evidências empíricas são favoráveis à hipótese de que os aumentos na aposentadoria influenciaram a trajetória do desemprego relativo dos trabalhadores não-qualificados. Embora o aumento no desemprego relativo desse grupo também tenha sido afetado por mudanças na demanda relativa por trabalho, parte desse aumento pode estar associado às aposentadorias domiciliares mais altas nos anos noventa. A maior pressão salarial dos trabalhadores não-qualificados, em função do salário de reserva mais alto, teria levado a um aumento nos rendimentos relativos desse grupo, mas também a aumentos nas taxas de desemprego e de desemprego de longo prazo bem mais acentuados do que para os semiqualificados e qualificados. Estes resultados sugerem que o aumento do desemprego ao longo dos anos noventa pode ter tido efeitos do ponto de vista de bem estar social dos trabalhadores menos qualificados, que são os mais pobres na distribuição da renda, muito menos deletérios do que inicialmente se supõe. Uma parte importante deste aumento decorre exatamente da melhoria da renda familiar per capita como resultado do aumento da importância da renda da aposentadoria para a família.

Deve-se ressaltar que várias mudanças importantes ocorreram na economia brasileira durante 0 período analisado neste trabalho, principalmente nos anos noventa. É possível, portanto, que efeitos associados às aposentadorias nas estimações estejam sendo provocados pelo comportamento de outros fatores. Como proposta para trabalhos futuros, pode-se tentar investigar a relação entre aposentadorias e decisões dos agentes no mercado de trabalho usando informações individuais para vários períodos de tempo. Acompanhando o mesmo indivíduo ao longo do tempo, seria possível, por exemplo, analisar melhor se o aumento na renda dos domicílios proveniente de aposentadorias levaria alguns trabalhadores a aceitar períodos mais longos de desemprego até encontrar um emprego melhor.

\section{Referências Bibliográficas}

Arulampalam, W. \& Stewart, M. (1995). The determinants of individual unemployment durations in an era of high unemployment. The Economic Journal, 105.

Atkinson, A. \& Micklewight, J. (1991). Unemployment compensation and labor market transitions: A critical review. Journal of Economic Literature, 29(4).

Baltagi, B. (1995). Econometric Analysis of Panel Data. John Wiley \& Sons.

Banerjee, A., Galiani, S., Levinsohn, J., McLaren, Z., \& Woolard, I. (2007). Why has unemployment risen in the new south Africa? Technical Report 13167, NBER.

Barros, R., Corseuil, C., \& Gonzaga, G. (1999). A evolução da demanda por trabalho na indústria brasileira: Evidências de dados por estabelecimento, 1985-1997. Pesquisa e planejamento Econômico, $31(2)$.

Blanchard, O. \& Diamond, P. (1989). The beveridge curve. Brookings Papers on Economic Activity, 1:1-60. 
Blanchard, O. \& Diamond, P. (1994). Ranking unemployment duration and wages. Review of Economic Studies, 61(3).

Blanchflower, D. \& Oswald, A. (1994). The Wage Curve. MIT Press, Cambridge, MA.

Bloemen, H. \& Stancanelli, E. (2001). Individual wealth, reservation wages, and transitions into employment. Journal of Labor Economics, 19(2).

Browning, M., Irish, M., \& Deaton, A. (1985). A profitable approach to labor supply on commodity demands over the life cycle. Econometrica, 53.

Camargo, J. M. \& Reis, M. C. (2005). Desemprego: O custo da desinformação. Revista Brasileira de Economia, 59(3).

Card, D. \& Hyslop, D. (1996). Does InflationGrease the wheels of the labor market? Technical Report 5538, NBER.

Deaton, A. (1985). Panel data from a time series of cross-sections. Journal of Econometrics, 30:109-126.

Deaton, A. \& Paxson, C. (1994). Saving, growth, and aging in Taiwan. In Wise, D., editor, Studies in the Economics of Aging. University of Chicago Press, Chicago.

Fernandes, R. \& Menezes-Filho, N. (2002). Escolaridade e demanda relativa por trabalho. In MenezesFilho, N. \& Chahad, J., editors, O Mercado de Trabalho No Brasil. LTR, São Paulo.

Fernandes, R. \& Picchetti, P. (1999). Uma análise da estrutura do desemprego e da inatividade no Brasil metropolitano. Pesquisa e Planejamento Econômico, 29(1).

Giambiagi, F. \& Além, A. C. (1997). A despesa previdenciária no Brasil: Evolução, diagnóstico e perspectivas. Technical Report 57, BNDES.

Gonzaga, G. (2003). Labor turnover and labor legislation in Brazil. Technical Report Discussion Paper 475, PUC-Rio, Economics Department, Rio de Janeiro.

Machin, S. \& Manning, A. (1999). The causes and consequences of longterm unemployment in Europe. In Ashenfelter, O. \& Card, D., editors, Handbook of Labor Economics. Elsevier.

Mare, R. (1980). Social background and school continuation decisions. Journal of the American Statistical Association, 75(374).

Najberg, S. \& Ikeda, M. (1999). Previdência no Brasil: Desafios e limites. In Giambiagi, F. \& Moreira, M., editors, A economia brasileira nos anos noventa. BNDES, Rio de Janeiro.

Pissarides, C. (2000). Equilibrium Unemployment Theory. The MIT Press.

Verbeek, F. \& Vella, M. (2008). Estimation of dynamic models from series of repeated cross-sections. Journal of Econometrics, (forthcoming).

\section{A. EFEITOS DA APOSENTADORIA SOBRE O DESEMPREGO E A PARTICIPAÇÃO}

Este apêndice procura descrever o mecanismo através do qual a aposentadoria, ou uma renda não necessariamente condicionada ao fato do trabalhador estar desempregado, pode influenciar o desemprego e a taxa de participação. Para isso, é considerado um modelo de uma economia com fluxos de entrada e saída de indivíduos do desemprego para o emprego, semelhante à Pissarides (2000). 
Nesse modelo empregos são criados e destruídos continuamente. A cada instante de tempo uma fração exógena s dos empregos, ocupados ou vagos, se torna não-produtiva e é fechada. Quando os empregos estão preenchidos, eles geram um nível de produção igual a $y$ a cada instante de tempo. A força de trabalho é normalizada para 1 , sendo que u indivíduos estão desempregados e $n=(1-u)$ estão empregados. As vagas oferecidas nessa economia são representadas por $v$, e a cada instante de tempo $h$ trabalhadores são contratados. O processo através do qual vagas e trabalhadores são encaixados é representado através da função matching: $h_{t}=m(u, v)$; onde $m_{u} \geq 0$ e $m_{v} \geq 0$, e $m(u, v)$ tem retornos constantes de escala. ${ }^{17}$ Portanto, a dinâmica do desemprego nessa economia é dada por: $\dot{u}=s(1-u)-h$.

Supondo uma função utilidade crescente e côncava, variações na renda proveniente da aposentadoria do próprio trabalhador ou de outro membro da família no domicílio, desde que esta renda seja distribuída entre os integrantes do domicílio, podem influenciar a taxa de desemprego de equilíbrio. ${ }^{18}$ De acordo com o modelo, um aumento na renda da aposentadoria no domicílio levaria a um aumento no salário de reserva dos trabalhadores, que se tornariam mais seletivos em relação às propostas de emprego. Esse aumento no salário de reserva faria com que a pressão salarial se tornasse maior. Com isso, o incentivo para a criação de vagas por parte das firmas diminuiria, já que os salários pagos aos trabalhadores seriam mais altos. Como resultado, a taxa de saída dos trabalhadores do desemprego diminuiria, provocando aumentos na taxa de desemprego de equilíbrio, assim como na duração do desemprego.

Já para descrever o efeito da aposentadoria sobre a decisão de cada indivíduo de participar do mercado de trabalho, são acrescentadas algumas hipóteses ao modelo. Seguindo Pissarides (2000), supomos que os trabalhadores fora da força de trabalho recebem uma utilidade $l_{0}$ proveniente do lazer. $O$ efeito do lazer sobre a utilidade varia entre os indivíduos por diferenças nas preferências, ${ }^{19}$ onde $l_{0}$ segue uma distribuição com densidade acumulada $\mathrm{H}\left(\mathrm{l}_{0}\right)$. Supomos também que essa utilidade com o lazer é complementar a renda do indivíduo.

A utilidade de um indivíduo que não participa do mercado de trabalho é $l_{0} g(A)$, onde $l_{0}>1 \mathrm{e} A$ é a renda com aposentadoria. Portanto, um indivíduo prefere participar do mercado de trabalho se $r V_{U}>$ $l_{0} g(A)$, ou seja, se o valor presente esperado da utilidade do indivíduo, caso esteja desempregado, for superior a utilidade obtida sem participar. Pode-se mostrar que isso é equivalente a seguinte condição: $\frac{(r+s) g(A)+(h / u) g(w+A)}{(r+s)+(h / u)}>l_{0} g(A)$.

Portanto, a regra que define a participação de um indivíduo com utilidade do lazer igual a $l_{0}$ é dada por: $P=\frac{(r+s) g(A)+(h / u) g(w+A)}{(r+s)+(h / u)}-l_{0} g(A)$.

Se $P>0$, o indivíduo participa. Caso contrário, ele prefere não participar do mercado de trabalho. O efeito de uma variação na aposentadoria sobre essa decisão pode ser avaliado pela derivada abaixo:

$$
\begin{aligned}
\frac{\partial P}{\partial A} & =\left\{\left[\left(1-l_{0}\right) g^{\prime}(A)(r+s)\right]+[g(w+A)-g(A)]\left(\frac{r+s}{D}\right) \frac{\partial(h / u)}{\partial A}\right. \\
& \left.+\left(\frac{h}{u}\right) g^{\prime}(w+A)\left[1+\frac{\partial w}{\partial(h / u)} \frac{\partial(h / u)}{\partial A}\right]-l_{0} g^{\prime}(A)\left(\frac{h}{u}\right)\right\} \frac{1}{D}
\end{aligned}
$$

onde $D=[r+s+(h / u)]>0$.

${ }^{17}$ Essa função resume as heterogeneidades, fricções e informações imperfeitas no mercado de trabalho, que fazem com que recursos sejam gastos na aquisição de informação e re-treinamento de empregados, por exemplo. Nessa função estão representados os investimentos de recursos por parte das firmas e dos trabalhadores nesse processo.

${ }^{18}$ Blanchard e Diamond (1989).

${ }^{19}$ Pissarides (2000) justifica a hipótese do lazer para indivíduos que não participam ser maior do que para os desempregados pelos custos de busca e pela indivisibilidade do tempo para algumas atividades de lazer. 
O primeiro termo da equação acima é negativo, pois $\left(1-l_{0}\right)<0$. O segundo termo também é negativo, já que $[g(w+A)-g(A)]>0$ e $\frac{\partial(h / u)}{\partial A}<0$, e pode-se mostrar que $\left[\frac{\partial w}{\partial(h / u)} \frac{\partial(h / u)}{\partial A}\right]>0$. Pelas características da função $g(\bullet)$, que fazem com que $\left[g^{\prime}(w+A)<g^{\prime}(A)\right]$, e pelo fato de que $l_{0}>1$, a soma do terceiro com o quarto termo deve ser negativa, exceto se a variação no salário proporcionada pelo aumento na aposentadoria for suficientemente elevada. Portanto, uma maior aposentadoria incentivaria a não-participação através da redução na taxa de saída do desemprego para o emprego, e pelo fato do lazer e a renda da aposentadoria serem complementares. Por outro lado, o aumento no salário de equilíbrio contribui para reduzir esse efeito. É importante notar que pelas características do modelo, com retornos constantes de escala para a função de produção e a função matching, mudanças na participação não influenciam os resultados para a taxa de desemprego.

Tabela 22 - Taxa de Participação dos Homens por Qualificação (\%) - 1981: 1999

\begin{tabular}{|c|c|c|c|c|}
\hline & $\begin{array}{c}\text { Não- } \\
\text { qualificados }\end{array}$ & $\begin{array}{c}\text { Semi- } \\
\text { qualificados }\end{array}$ & Qualificados & Total \\
\hline Ano & $(1)$ & $(2)$ & $(3)$ & $(4)$ \\
\hline 81 & 89,43 & 93,06 & 95,28 & 92,14 \\
82 & 89,79 & 93,01 & 96,05 & 92,38 \\
83 & 89,51 & 92,87 & 95,46 & 92,21 \\
84 & 88,63 & 92,59 & 95,47 & 91,80 \\
85 & 89,42 & 92,91 & 95,79 & 92,39 \\
86 & 89,36 & 92,72 & 95,55 & 92,31 \\
87 & 89,97 & 93,88 & 96,03 & 93,19 \\
88 & 90,01 & 93,28 & 95,84 & 92,90 \\
89 & 89,06 & 93,04 & 96,09 & 92,62 \\
90 & 89,14 & 93,31 & 94,87 & 92,53 \\
92 & 88,88 & 92,44 & 95,21 & 92,10 \\
93 & 88,26 & 92,75 & 95,03 & 92,07 \\
95 & 87,68 & 92,90 & 94,99 & 92,04 \\
96 & 86,24 & 91,47 & 94,12 & 90,85 \\
97 & 86,95 & 91,71 & 94,32 & 91,24 \\
98 & 86,20 & 91,04 & 94,02 & 90,73 \\
99 & 86,51 & 91,42 & 93,75 & 90,94 \\
\hline$\Delta(99-81)$ & $-2,91$ & $-1,64$ & $-1,54$ & $-1,20$ \\
\hline$\Delta(90-81)$ & $-0,29$ & 0,24 & $-0,42$ & 0,40 \\
\hline$\Delta(99-90)$ & $-2,62$ & $-1,88$ & $-1,12$ & $-1,59$ \\
\hline
\end{tabular}

Fonte: PNAD. A amostra é formada pelos homens residentes nas áreas urbanas entre 25 e 59 anos. 
Tabela 23 - Taxa de Participação das Mulheres por Qualificação (\%) - 1981: 1999

\begin{tabular}{|c|c|c|c|c|}
\hline & Não- & Semi- & Qualificados & Total \\
\hline & qualificados & qualificados & & $(4)$ \\
\hline 81 & $(1)$ & $(2)$ & $(3)$ & 39,30 \\
82 & 30,74 & 36,60 & 67,74 & 42,18 \\
83 & 34,35 & 39,07 & 68,95 & 42,37 \\
84 & 34,46 & 38,73 & 68,54 & 43,40 \\
85 & 34,99 & 39,98 & 68,90 & 44,77 \\
86 & 35,94 & 40,72 & 69,91 & 46,09 \\
87 & 36,16 & 42,71 & 70,85 & 47,94 \\
88 & 39,07 & 44,12 & 70,01 & 48,89 \\
89 & 38,93 & 44,80 & 71,07 & 49,28 \\
90 & 38,62 & 45,29 & 71,05 & 50,12 \\
92 & 40,42 & 45,42 & 70,49 & 53,73 \\
93 & 42,83 & 50,27 & 73,29 & 54,05 \\
95 & 42,15 & 50,68 & 73,73 & 56,98 \\
96 & 44,61 & 53,87 & 74,98 & 55,97 \\
97 & 42,63 & 52,72 & 73,92 & 57,21 \\
98 & 43,21 & 53,37 & 75,49 & 58,23 \\
99 & 44,31 & 54,55 & 75,18 & 59,88 \\
\hline$\Delta(99-81)$ & 46,16 & 56,29 & 75,19 & 20,58 \\
$\Delta(90-81)$ & 15,43 & 19,69 & 7,44 & 10,82 \\
$\Delta(99-90)$ & 9,69 & 8,82 & 2,74 & 9,76 \\
\hline
\end{tabular}

Fonte: PNAD. A amostra é formada pelas mulheres residentes nas áreas urbanas entre 25 e 59 anos. 
Tabela 24 - Número de Observações nas Coortes

\begin{tabular}{|c|c|c|c|c|c|c|}
\hline \multirow[b]{2}{*}{$\begin{array}{c}\text { Ano de } \\
\text { nascimento }\end{array}$} & \multicolumn{2}{|c|}{ Não-qualificados } & \multicolumn{2}{|c|}{ Semi-qualificados } & \multicolumn{2}{|c|}{ Qualificados } \\
\hline & $\begin{array}{c}\text { Número } \\
\text { médio de } \\
\text { observações } \\
\text { por célula }\end{array}$ & $\begin{array}{c}\text { Número } \\
\text { mínimo de } \\
\text { observações } \\
\text { por célula }\end{array}$ & $\begin{array}{c}\text { Número } \\
\text { médio de } \\
\text { observações } \\
\text { por célula }\end{array}$ & $\begin{array}{c}\text { Número } \\
\text { mínimo de } \\
\text { observações } \\
\text { por célula }\end{array}$ & $\begin{array}{c}\text { Número } \\
\text { médio de } \\
\text { observações } \\
\text { por célula }\end{array}$ & $\begin{array}{c}\text { Número } \\
\text { mínimo de } \\
\text { observações } \\
\text { por célula }\end{array}$ \\
\hline 1922 & 427 & 427 & 263 & 263 & 103 & 103 \\
\hline 1923 & 404 & 379 & 287 & 271 & 80 & 79 \\
\hline 1924 & 499 & 475 & 310 & 289 & 103 & 78 \\
\hline 1925 & 521 & 448 & 326 & 259 & 110 & 89 \\
\hline 1926 & 519 & 462 & 353 & 288 & 119 & 90 \\
\hline 1927 & 534 & 233 & 357 & 158 & 127 & 53 \\
\hline 1928 & 511 & 265 & 377 & 184 & 128 & 59 \\
\hline 1929 & 507 & 272 & 388 & 161 & 129 & 54 \\
\hline 1930 & 575 & 344 & 418 & 218 & 152 & 74 \\
\hline 1931 & 491 & 288 & 391 & 193 & 149 & 77 \\
\hline 1932 & 559 & 299 & 434 & 218 & 162 & 76 \\
\hline 1933 & 515 & 305 & 412 & 209 & 167 & 81 \\
\hline 1934 & 516 & 264 & 443 & 209 & 168 & 74 \\
\hline 1935 & 587 & 317 & 514 & 240 & 200 & 97 \\
\hline 1936 & 585 & 307 & 530 & 243 & 216 & 106 \\
\hline 1937 & 583 & 305 & 520 & 256 & 220 & 111 \\
\hline 1938 & 578 & 321 & 550 & 227 & 235 & 103 \\
\hline 1939 & 583 & 322 & 576 & 293 & 247 & 121 \\
\hline 1940 & 678 & 370 & 650 & 326 & 291 & 139 \\
\hline 1941 & 571 & 357 & 596 & 309 & 288 & 146 \\
\hline 1942 & 677 & 397 & 677 & 341 & 348 & 194 \\
\hline 1943 & 630 & 408 & 710 & 403 & 355 & 177 \\
\hline 1944 & 672 & 440 & 740 & 432 & 397 & 233 \\
\hline 1945 & 673 & 418 & 806 & 495 & 467 & 314 \\
\hline 1946 & 665 & 460 & 842 & 542 & 502 & 333 \\
\hline 1947 & 688 & 466 & 911 & 530 & 568 & 351 \\
\hline 1948 & 712 & 477 & 1003 & 685 & 629 & 397 \\
\hline 1949 & 691 & 511 & 1015 & 690 & 681 & 482 \\
\hline 1950 & 759 & 554 & 1168 & 830 & 770 & 557 \\
\hline 1951 & 692 & 501 & 1173 & 822 & 790 & 599 \\
\hline 1952 & 699 & 512 & 1280 & 912 & 859 & 656 \\
\hline 1953 & 670 & 498 & 1324 & 975 & 921 & 725 \\
\hline 1954 & 675 & 504 & 1442 & 1061 & 989 & 767 \\
\hline 1955 & 676 & 442 & 1481 & 1145 & 1033 & 796 \\
\hline 1956 & 646 & 488 & 1521 & 1125 & 1072 & 840 \\
\hline 1957 & 618 & 412 & 1553 & 1117 & 1091 & 864 \\
\hline 1958 & 611 & 449 & 1554 & 1208 & 1101 & 871 \\
\hline 1959 & 548 & 432 & 1513 & 1205 & 1094 & 894 \\
\hline 1960 & 590 & 442 & 1534 & 1294 & 1126 & 898 \\
\hline 1961 & 507 & 409 & 1381 & 1235 & 1031 & 873 \\
\hline 1962 & 532 & 423 & 1494 & 1372 & 1118 & 975 \\
\hline 1963 & 561 & 421 & 1570 & 1401 & 1191 & 1059 \\
\hline 1964 & 542 & 433 & 1621 & 1508 & 1214 & 1059 \\
\hline 1965 & 541 & 432 & 1661 & 1527 & 1229 & 1086 \\
\hline 1966 & 557 & 491 & 1627 & 1593 & 1230 & 1118 \\
\hline 1967 & 510 & 475 & 1605 & 1501 & 1163 & 992 \\
\hline 1968 & 506 & 468 & 1713 & 1646 & 1166 & 1046 \\
\hline 1969 & 504 & 437 & 1696 & 1625 & 1172 & 1084 \\
\hline 1970 & 502 & 450 & 1767 & 1674 & 1241 & 1136 \\
\hline 1971 & 447 & 409 & 1691 & 1655 & 1214 & 1100 \\
\hline 1972 & 467 & 423 & 1795 & 1753 & 1316 & 1287 \\
\hline 1973 & 460 & 437 & 1748 & 1735 & 1368 & 1350 \\
\hline 1974 & 431 & 431 & 1793 & 1793 & 1445 & 1445 \\
\hline
\end{tabular}

Fonte: PNAD. A amostra é formada pelos indivíduos residentes nas áreas urbanas, com idades entre 25 e 59 anos e que participam da PEA. 
Tabela 25 - Regressões Logit para a Probabilidade de Desemprego (não-qualificados)

\begin{tabular}{|c|c|c|c|c|c|c|}
\hline & (i) & (ii) & (iii) & (iv) & (v) & (vi) \\
\hline & \begin{tabular}{|c|} 
Coeficiente \\
Marginais \\
\end{tabular} & Efeitos & $\begin{array}{l}\text { Coeficiente } \\
\text { Marginais }\end{array}$ & Efeitos & \begin{tabular}{c|} 
Coeficiente \\
Marginais
\end{tabular} & Efeitos \\
\hline Aposentadoria domiciliar per capita & $\begin{array}{l}0,001 \\
(6.19)\end{array}$ & 0,012 & $\begin{array}{l}0,002 \\
(6.71)\end{array}$ & 0,008 & $\begin{array}{l}0,001 \\
(3.62)\end{array}$ & 0,005 \\
\hline Idade & $\begin{array}{l}-0,147 \\
(2.20)\end{array}$ & $-1,19$ & $\begin{array}{l}-0,14 \\
(2.10)\end{array}$ & $-0,70$ & $\begin{array}{l}-0,15 \\
(2.18)\end{array}$ & $-0,54$ \\
\hline Idade ao quadrado & $\begin{array}{c}0,0045 \\
(2.70)\end{array}$ & 0,04 & $\begin{array}{l}0,004 \\
(2.63)\end{array}$ & 0,02 & $\begin{array}{l}0,004 \\
(2.67)\end{array}$ & 0,02 \\
\hline Idade ao cubo & $\begin{array}{c}-0,00003 \\
(2.43)\end{array}$ & 0,00 & $\begin{array}{c}-0,00003 \\
(2.39)\end{array}$ & 0,00 & $\begin{array}{c}-0,00003 \\
(2.4)\end{array}$ & 0,00 \\
\hline Gênero & $\begin{array}{c}0,241 \\
(12.66)\end{array}$ & 1,95 & $\begin{array}{c}0,23 \\
(12.18)\end{array}$ & 1,15 & $\begin{array}{c}0,26 \\
(13.31)\end{array}$ & 0,95 \\
\hline Nordeste & $\begin{array}{l}0,137 \\
(3.80)\end{array}$ & 1,11 & $\begin{array}{c}0,12 \\
(3.37)\end{array}$ & 0,60 & $\begin{array}{c}0,14 \\
(3.74)\end{array}$ & 0,50 \\
\hline Sudeste & $\begin{array}{l}0,250 \\
(6.93)\end{array}$ & 2,03 & $\begin{array}{c}0,25 \\
(6.93)\end{array}$ & 1,23 & $\begin{array}{c}0,25 \\
(6.92)\end{array}$ & 0,93 \\
\hline Sul & $\begin{array}{l}0,236 \\
(5.80)\end{array}$ & 1,91 & $\begin{array}{c}0,24 \\
(5.82)\end{array}$ & 1,17 & $\begin{array}{c}0,24 \\
(5.84)\end{array}$ & 0,88 \\
\hline Centro-Oeste & $\begin{array}{c}0,1294 \\
(3.10)\end{array}$ & 1,05 & $\begin{array}{c}0,13 \\
(3.02)\end{array}$ & 0,62 & $\begin{array}{c}0,13 \\
(3.12)\end{array}$ & 0,48 \\
\hline PIB & $\begin{array}{c}-3,56 \\
(12.46)\end{array}$ & $-28,81$ & $\begin{array}{c}-3,54 \\
(12.39)\end{array}$ & $-17,39$ & $\begin{array}{c}-3,57 \\
(12.48)\end{array}$ & $-13,22$ \\
\hline Inflação & $\begin{array}{l}-0,003 \\
(3.67)\end{array}$ & $-0,03$ & $\begin{array}{l}-0,003 \\
(3.64)\end{array}$ & $-0,02$ & $\begin{array}{l}-0,003 \\
(3.76)\end{array}$ & $-0,01$ \\
\hline Intercepto & $\begin{array}{l}-4,69 \\
(4.66)\end{array}$ & $-37,95$ & $\begin{array}{l}-4,74 \\
(4.68)\end{array}$ & $-23,26$ & $\begin{array}{l}-4,72 \\
(4.69)\end{array}$ & $-17,51$ \\
\hline Aposentadoria do indivíduo & $\begin{array}{c}-0,000001 \\
(1.78)\end{array}$ & & & & & \\
\hline $\begin{array}{l}\text { Razão entre o nímero de crianças com menos } \\
\text { de } 10 \text { anos no domicílio e o número de adultos }\end{array}$ & & & $\begin{array}{l}-0,15 \\
(2.96)\end{array}$ & $-0,75$ & & \\
\hline Aposentado no domicílio que & & & $-0,19$ & $-0,95$ & & \\
\hline participa da PEA & & & $(2.73)$ & & & \\
\hline $\begin{array}{l}\text { Escolaridade média dos outros membros } \\
\text { do domicílio }\end{array}$ & & & $\begin{array}{l}-0,03 \\
(7.88)\end{array}$ & $-0,13$ & & \\
\hline Filho do aposentado & & & & & $\begin{array}{l}0,003 \\
(5.54)\end{array}$ & 0,01 \\
\hline Cônjuge do aposentado & & & & & $\begin{array}{l}-0,003 \\
(2.39)\end{array}$ & $-0,01$ \\
\hline Dummies de coorte & Sim & & Sim & & Sim & \\
\hline $\begin{array}{l}\text { Observações } \\
\text { Pseudo-R2 }\end{array}$ & $\begin{array}{c}362837 \\
0,04\end{array}$ & & $\begin{array}{c}362837 \\
0,04\end{array}$ & & $\begin{array}{c}362837 \\
0,04\end{array}$ & \\
\hline
\end{tabular}

Fonte: PNAD.

As estatísticas-t são mostradas entre parênteses.

Os efeitos marginais são calculados para o grupo de referência formado por: homens, de 40 anos, na região sudeste, nascidos em 1960. Para o PIB e a inflação são utilizadas as médias para todo o período. A aposentadoria domiciliar per capita é a média de todo o período para cada grupo de qualificação. 
Tabela 26 - Regressões Logit para a Probabilidade de Desemprego (semi-qualificados)

\begin{tabular}{|c|c|c|c|c|c|c|}
\hline & (i) & (ii) & (iii) & (iv) & (v) & (vi) \\
\hline & \begin{tabular}{|c|} 
Coeficiente \\
Marginais
\end{tabular} & Efeitos & \begin{tabular}{|c|} 
Coeficiente \\
Marginais
\end{tabular} & Efeitos & \begin{tabular}{|c|} 
Coeficiente \\
Marginais
\end{tabular} & Efeitos \\
\hline Aposentadoria domiciliar per capita & $\begin{array}{c}0,0011 \\
8.68\end{array}$ & 0,0064 & $\begin{array}{c}0,0011 \\
8,1\end{array}$ & 0,0048 & $\begin{array}{c}0,0009 \\
3,58\end{array}$ & 0,0056 \\
\hline Idade & $\begin{array}{l}-0,25 \\
-4,85\end{array}$ & $-1,50$ & $\begin{array}{l}-0,21 \\
-3,96\end{array}$ & $-0,93$ & $\begin{array}{l}-0,25 \\
-4,77\end{array}$ & $-1,52$ \\
\hline Idade ao quadrado & $\begin{array}{l}0,01 \\
4,43\end{array}$ & 0,04 & $\begin{array}{l}0,01 \\
3,67\end{array}$ & 0,02 & $\begin{array}{l}0,01 \\
4,34\end{array}$ & 0,04 \\
\hline Idade ao cubo & $\begin{array}{r}0,00 \\
-3,42\end{array}$ & 0,00 & $\begin{array}{r}0,00 \\
-2,76\end{array}$ & 0,00 & $\begin{array}{c}0,00 \\
-3,29\end{array}$ & 0,00 \\
\hline Gênero & $\begin{array}{c}0,37 \\
26,98\end{array}$ & 2,17 & $\begin{array}{c}0,33 \\
24,18\end{array}$ & 1,48 & $\begin{array}{c}0,38 \\
28,04\end{array}$ & 2,34 \\
\hline Nordeste & $\begin{array}{l}0,26 \\
9,53\end{array}$ & 1,54 & $\begin{array}{l}0,24 \\
8,92\end{array}$ & 1,08 & $\begin{array}{l}0,26 \\
9,47\end{array}$ & 1,58 \\
\hline Sudeste & $\begin{array}{l}0,11 \\
4,35\end{array}$ & 0,67 & $\begin{array}{l}0,10 \\
3,97\end{array}$ & 0,46 & $\begin{array}{l}0,11 \\
4,25\end{array}$ & 0,67 \\
\hline Sul & $\begin{array}{l}-0,16 \\
-5,51\end{array}$ & $-0,95$ & $\begin{array}{l}-0,16 \\
-5,58\end{array}$ & $-0,72$ & $\begin{array}{l}-0,16 \\
-5,48\end{array}$ & $-0,97$ \\
\hline Centro-Oeste & $\begin{array}{c}-0,08 \\
-2,7\end{array}$ & $-0,50$ & $\begin{array}{l}-0,09 \\
-2,86\end{array}$ & $-0,40$ & $\begin{array}{l}-0,08 \\
-2,69\end{array}$ & $-0,51$ \\
\hline PIB & $\begin{array}{c}-2,83 \\
-12,78\end{array}$ & $-16,74$ & $\begin{array}{l}-2,79 \\
-12,58\end{array}$ & $-12,34$ & $\begin{array}{c}-2,83 \\
-12,79\end{array}$ & $-17,32$ \\
\hline Inflação & $\begin{array}{r}0,00 \\
-5,11\end{array}$ & $-0,02$ & $\begin{array}{r}0,00 \\
-4,86\end{array}$ & $-0,01$ & $\begin{array}{r}0,00 \\
-5,08\end{array}$ & $-0,02$ \\
\hline Intercepto & $\begin{array}{l}-1,97 \\
-2,36\end{array}$ & $-11,69$ & $\begin{array}{l}-2,42 \\
-2,87\end{array}$ & $-10,69$ & $\begin{array}{l}-2,07 \\
-2,48\end{array}$ & $-12,65$ \\
\hline Aposentadoria do indivíduo & $\begin{array}{l}0,00 \\
1,77\end{array}$ & & & & & \\
\hline $\begin{array}{l}\text { Razão entre o nímero de crianças com menos } \\
\text { de } 10 \text { anos no domicílio e o número de adultos } \\
\text { Aposentado no domicílio que } \\
\text { participa da PEA } \\
\text { Escolaridade média dos outros membros } \\
\text { do domicílio }\end{array}$ & & & $\begin{array}{r}-0,29 \\
-7,75 \\
0,07 \\
1,63 \\
-0,04 \\
-18,77\end{array}$ & $\begin{array}{c}-1,27 \\
0,31 \\
-0,17\end{array}$ & . & \\
\hline $\begin{array}{l}\text { Filho do aposentado } \\
\text { Cônjuge do aposentado }\end{array}$ & & & & & $\begin{array}{r}0,00 \\
5,51 \\
0,00 \\
-5,51\end{array}$ & $\begin{array}{l}0,01 \\
-0,02\end{array}$ \\
\hline Dummies de coorte & Sim & & Sim & & Sim & \\
\hline $\begin{array}{l}\text { Observações } \\
\text { Pseudo-R2 }\end{array}$ & $\begin{array}{c}600616 \\
0,041\end{array}$ & & $\begin{array}{c}600616 \\
0,043\end{array}$ & & $\begin{array}{c}600616 \\
0,042\end{array}$ & \\
\hline
\end{tabular}

Fonte: PNAD.

As estatísticas-t são mostradas entre parênteses.

Os efeitos marginais são calculados para o grupo de referência formado por: homens, de 40 anos, na região sudeste, nascidos em 1960. Para o PIB e a inflação são utilizadas as médias para todo o período. A aposentadoria domiciliar per capita é a média de todo o período para cada grupo de qualificação. 
Tabela 27 - Regressões Logit para a Probabilidade de Desemprego (qualificados)

\begin{tabular}{|c|c|c|c|c|c|c|}
\hline & (i) & (ii) & (iii) & (iv) & (v) & (vi) \\
\hline & $\begin{array}{l}\text { Coeficiente } \\
\text { Marginais }\end{array}$ & Efeitos & $\begin{array}{l}\text { Coeficiente } \\
\text { Marginais }\end{array}$ & Efeitos & \begin{tabular}{|c|} 
Coeficiente \\
Marginais \\
\end{tabular} & Efeitos \\
\hline Aposentadoria domiciliar per capita & $\begin{array}{c}0,0005 \\
14,86\end{array}$ & 0,0019 & $\begin{array}{c}0,0005 \\
13,01\end{array}$ & 0,0011 & $\begin{array}{c}0,0005 \\
10,86\end{array}$ & 0,0019 \\
\hline Idade & $\begin{array}{l}-0,31 \\
-3,81\end{array}$ & $-1,16$ & $\begin{array}{l}-0,21 \\
-2,57\end{array}$ & $-0,50$ & $\begin{array}{l}-0,31 \\
-3,82\end{array}$ & $-1,16$ \\
\hline Idade ao quadrado & $\begin{array}{l}0,01 \\
2,98\end{array}$ & 0,02 & $\begin{array}{l}0,00 \\
1,96\end{array}$ & 0,01 & $\begin{array}{l}0,01 \\
2,99\end{array}$ & 0,02 \\
\hline Idade ao cubo & $\begin{array}{l}0,00 \\
-1,70\end{array}$ & 0,00 & $\begin{array}{r}0,00 \\
-0,89\end{array}$ & 0,00 & $\begin{array}{l}0,00 \\
-1,69\end{array}$ & 0,00 \\
\hline Gênero & $\begin{array}{c}0,41 \\
20,20\end{array}$ & 1,53 & $\begin{array}{c}0,36 \\
17,44\end{array}$ & 0,85 & $\begin{array}{c}0,41 \\
20,58\end{array}$ & 1,56 \\
\hline Nordeste & $\begin{array}{l}0,09 \\
2,50\end{array}$ & 0,35 & $\begin{array}{l}0,08 \\
2,28\end{array}$ & 0,20 & $\begin{array}{l}0,09 \\
2,42\end{array}$ & 0,34 \\
\hline Sudeste & $\begin{array}{l}-0,05 \\
-1,30\end{array}$ & $-0,17$ & $\begin{array}{l}-0,04 \\
-1,18\end{array}$ & $-0,10$ & $\begin{array}{l}-0,05 \\
-1,41\end{array}$ & $-0,19$ \\
\hline Sul & $\begin{array}{l}-0,38 \\
-9,19\end{array}$ & $-1,45$ & $\begin{array}{l}-0,37 \\
-8,78\end{array}$ & $-0,88$ & $\begin{array}{l}-0,39 \\
-9,24\end{array}$ & $-1,45$ \\
\hline Centro-Oeste & $\begin{array}{l}-0,36 \\
-8,06\end{array}$ & $-1,34$ & $\begin{array}{l}-0,34 \\
-7,67\end{array}$ & $-0,81$ & $\begin{array}{l}-0,36 \\
-8,08\end{array}$ & $-1,34$ \\
\hline PIB & $\begin{array}{l}-2,39 \\
-6,93\end{array}$ & $-9,00$ & $\begin{array}{l}-2,34 \\
-6,79\end{array}$ & $-5,57$ & $\begin{array}{l}-2,41 \\
-6,99\end{array}$ & $-9,05$ \\
\hline Inflação & $\begin{array}{r}0,00 \\
-4,22\end{array}$ & $-0,02$ & $\begin{array}{r}0,00 \\
-3,90\end{array}$ & $-0,01$ & $\begin{array}{r}0,00 \\
-4,13\end{array}$ & $-0,01$ \\
\hline $\begin{array}{l}\text { Intercepto } \\
\text { Aposentadoria do indivíduo }\end{array}$ & $\begin{array}{r}-1,06 \\
-0,81 \\
0,00 \\
4,14\end{array}$ & $\begin{array}{l}-3,98 \\
0,00\end{array}$ & $\begin{array}{l}-2,06 \\
-1,55\end{array}$ & $-4,89$ & $\begin{array}{l}-1,11 \\
-0,86\end{array}$ & $-4,19$ \\
\hline $\begin{array}{l}\text { Razão entre o nímero de crianças com menos } \\
\text { de } 10 \text { anos no domicílio e o número de adultos } \\
\text { Aposentado no domicílio que } \\
\text { participa da PEA } \\
\text { Escolaridade média dos outros membros } \\
\text { do domicílio }\end{array}$ & & & $\begin{array}{l}-0,34 \\
-5,88 \\
0,21 \\
5,88 \\
-0,04 \\
-20,34\end{array}$ & $\begin{array}{l}-0,80 \\
0,50 \\
-0,10\end{array}$ & . & \\
\hline $\begin{array}{l}\text { Filho do aposentado } \\
\text { Cônjuge do aposentado }\end{array}$ & & & & & $\begin{array}{r}0,00 \\
2,98 \\
0,00 \\
-4,16 \\
\end{array}$ & $\begin{array}{l}0,001 \\
-0,003\end{array}$ \\
\hline Dummies de coorte & Sim & & Sim & & Sim & \\
\hline $\begin{array}{l}\text { Observações } \\
\text { Pseudo-R2 }\end{array}$ & $\begin{array}{l}384758 \\
0,0468\end{array}$ & & $\begin{array}{l}384758 \\
0,0521\end{array}$ & & $\begin{array}{l}384758 \\
0,0472 \\
\end{array}$ & \\
\hline
\end{tabular}

Fonte: PNAD.

As estatísticas-t são mostradas entre parênteses.

Os efeitos marginais são calculados para o grupo de referência formado por: homens, de 40 anos, na região sudeste, nascidos em 1960. Para o PIB e a inflação são utilizadas as médias para todo o período. A aposentadoria domiciliar per capita é a média de todo o período para cada grupo de qualificação. 